\title{
LA DIÓCESIS EPISCOPAL EN LA HISPANIA VISIGODA: CONCEPCIÓN, CONSTRUCCIÓN Y DISPUTAS POR SU TERRITORIO*
}

\author{
POR \\ PABlo POVEdA ARIAS ${ }^{1}$ \\ Universidad de Salamanca
}

\begin{abstract}
RESUMEN
El período tardoantiguo asistió al florecimiento y consolidación del poder episcopal como uno de sus fenómenos más reseñables. Este proceso trajo consigo la construcción de un espacio eclesiástico sobre el que los prelados ejercerán su misión pastoral, la diócesis, a la cual dedicamos el presente artículo. Para ello centraremos nuestro marco de estudio en el período hispanovisigodo. En primer lugar, ahondaremos en la percepción de la misma, tanto como realidad espacial como social. Esta cuestión nos llevará directamente a analizar los mecanismos de construcción de la jurisdicción diocesana, para terminar con una relectura de las disputas episcopales por el territorio.
\end{abstract}

PALABRAS CLAVE: Antigüedad tardía; competencia; Historia de la Iglesia; Historia social; iglesias rurales; obispos.

\section{EPISCOPAL DIOCESES IN VISIGOTHIC SPAIN: ORIGINS, CONSTRUCTION, AND TERRITORIAL DISPUTES}

\begin{abstract}
Late Antiquity was the backdrop for one of the most remarkable phenomena of the period, the development and consolidation of Episcopal power. This process entailed the construction of dioceses, the ecclesiastic spaces in which bishops would exert their pastoral mission and the object of this study. In this paper we will focus our research on the framework of Visigothic Spain, starting with an analysis of the perception of dioceses as social and spatial realities and followed by a study of the mechanisms whereby diocesan jurisdiction was constructed. Finally, we will conclude with a review of Episcopal conflicts over territorial issues.
\end{abstract}

KEY WORDS: Late Antiquity; Competition; Church History; Social History; Rural churches; Bishops.

Cómo CITAR ESTE ARTículo / CitATION: Poveda Arias, P. 2019. «La diócesis episcopal en la Hispania visigoda: concepción, construcción y disputas por su territorio». Hispania Sacra 71, 143: 9-24. https://doi.org/10.3989/hs.2019.001

Recibido/Received: 12-01-2018

Aceptado/Accepted: $\quad 01-10-2018$

\section{INTRODUCCIÓN}

Los últimos dos siglos de vigencia del Imperio romano en Occidente asistieron a la aparición y consolidación de

* Este trabajo ha sido desarrollado dentro del proyecto de investigación HAR2016-76094 «Formación y dinámica de los espacios comunales ganaderos en el Noroeste de la península ibérica medieval: paisajes e identidades sociales en perspectiva comparada» financiado por el Ministerio de Economía y Competitividad y en el marco del programa de Formación del Profesorado Universitario (FPU) del Ministerio de Educación, Cultura y Deporte (Ref. FPU13/02473). Mi agradecimiento más sincero a P. C. Díaz, I. Fuentes y a los evaluadores anónimos, cuyos comentarios y sugerencias han contribuido a mejorar y enriquecer el resultado final que aquí se presenta. No obstante, todo lo puesto de manifiesto a lo largo de presente estudio es responsabilidad única de quien suscribe sus líneas.

1 pablop@usal.es / ORCID iD: https://orcid.org/0000-00022691-7912 una nueva figura de liderazgo ciudadano, el obispo, quien en el mismo proceso de disolución de la influencia imperial emergerá en muchas ocasiones como la autoridad política y social por excelencia de las comunidades sobre las que ejercía su misión pastoral. ${ }^{2}$ Dentro de este contexto, los obispos absorberán buena parte de las funciones que hasta aquellos momentos habían venido desempeñando las magistraturas e instituciones imperiales. ${ }^{3}$ Todo ello, además, en un mundo

2 En lo referido a Hispania, el caso más paradigmático es sin lugar a dudas el de Mérida. Cf. Collins 1980: 189-210, una posición que le habría permitido rivalizar incluso con el poder central visigodo y gozar de una amplia autonomía hasta el último tercio del siglo VI.

3 Sobre el florecimiento de la figura episcopal en el Occidente tardoantiguo la bibliografía es ingente. Únicamente a modo de ejemplo, Mor 1979: 7-33; Rapp 2005, el cual constituye el trabajo de referencia sobre la cuestión; Castellanos 2016: 101-115. Sobre la arrogación 
contraído claramente a un plano eminentemente local y regional, en el que se desarrollarán poderes completamente autónomos, entre los que incluimos a los propios obispos. ${ }^{4}$ El caso de Hispania es un claro ejemplo donde todas estas dinámicas se hicieron claramente patentes, aunque con una diversidad regional a tener en cuenta. ${ }^{5}$

En este escenario claramente fragmentado y localizado, la ciudad sobresaldrá como unidad básica de funcionamiento político y social durante los siglos $\mathrm{V}$ y $\mathrm{VI},{ }^{6}$ aunque con distintos niveles de desarrollo urbano en función de cada región, ${ }^{7}$ convirtiéndose así en los centros preferentes de acción episcopal a través de los cuales se ejercía un control sobre el territorio. Como bien es sabido, el espacio bajo jurisdicción del obispo es la diócesis, que constituía su base territorial de actuación. ${ }^{8}$ La historiografía ha dado por sentado que desde el principio las diócesis y, por extensión, las provincias eclesiásticas conformaban realidades claramente delimitadas, extrapolando e incluso asimilando las unidades administrativas tardorromanas a las propias de la Iglesia. Aunque no dudamos que originalmente los marcos administrativos del Imperio sirviesen de forma temporal para la organización espacial de los asuntos espirituales, ${ }^{9}$ la disolución de las estructuras de gobierno imperiales habría influido enormemente en las dinámicas eclesiásticas post-romanas, alterando así los patrones preexistentes de definición territorial. De esta manera, y como hipótesis de partida, creemos que en el período tardoantiguo y altomedieval el territorio no se definía tanto por una delimitación clara del mismo, sino por otras prácticas espaciales que, obviamente, habrían influido en su concepción y, por consiguiente, en la propia percepción que las fuentes transmiten de él. En concreto, consideramos que será la propia acción social sobre el espacio la que construirá en primer término el territorio y no tanto la preocupación por su delimitación, ${ }^{10}$ la cual en todo caso vendría con posterioridad. ${ }^{11}$ La tendencia general a dar por supuestas para

paulatina de funciones de gobierno por parte del obispo en el contexto ibérico, véase García Moreno 1990: 223-258; Pérez Martínez 2000-2001: 17-40; Ubric Rabaneda 2004. Sobre su capacidad para establecer redes personales de poder en torno a su figura, Fuentes Hinojo 2008: 315-344.

4 Sobre el particular, véase Van Dam 1985: 141-156; Halsall 2007: 338-346; Escalona Monge 2011: 25-26; Brown 2012: 392-400.

5 Cf. García Moreno 1990: 223-258; Castellanos y Martín Viso 2005: 1-43; Díaz y Menéndez Bueyes 2005: 265-297; Wickham 2005: 221-226; Escalona Monge 2006: 165-199. Desde una perspectiva arqueológica, Quirós Castillo 2011: 285-311.

6 Desde una perspectiva general, García Moreno 1999: 7-23; Liebeschuetz 2001; Wickham 2009: 61-80; Dey 2014. Circunscribiéndose al ámbito hispano, Díaz 2000: 3-35; Kulikowski 2004.

7 El caso de la Meseta es quizás el que mayor rango diferencia presenta con el patrón general de la Península. Posiblemente sea esta la región donde el nivel de atomización y localización de las estructuras de poder se hizo más patente, advirtiendo así una mayor desarticulación de la red urbana, como bien ilustra el caso de Clunia; aunque la ciudad pervivió como célula de poblamiento preeminente. Cf. Abasolo 1999: 93; Cepas 2006: 187-207.

8 Nos quedamos con la definición ofrecida por M. Lauwers (2008: 24): «ce que nous appelons 'diocèse' est donc un siège qui command une zone d'influence, laquelle s'inscrit au sein d'une hiérarchie tout à la fois administrative et spatiale».

9 Barbero de Aguilera 1989: 169-170; Gurt et alii 1993: 168.

10 Aunque profundizaremos más adelante sobre esta cuestión, para un caso de estudio, véase Morsel 2006a: 295-316.

11 Somos conscientes de que en este punto nos movemos en el plano de la hipótesis, puesto que no disponemos de datos contundentes que apunten ya sea a la imposición en primer lugar de un control estos momentos unas circunscripciones claramente definidas e inmutables y, como consecuencia de ello, a percibir unos territorios unificados es una herencia de la antigua geografía histórica que, indudablemente, puede abrirse a la crítica. ${ }^{12}$

A tenor de este punto de partida, nuestro propósito a través de las siguientes páginas es plantear una reformulación del concepto diocesano como realidad espacial en el período de vigencia del reino visigodo en Hispania (507-711). En concreto pretendemos buscar una alternativa a la percepción «delimitada» que impera en la historiografía especializada al concebir la diócesis como una circunscripción territorial claramente definida. Para la consecución de este objetivo, tendrá especial utilidad el estudio de las dinámicas formativas del espacio sobre la que el obispo ejercía su jurisdicción. Para todo ello, las actas conciliares conservadas, tanto en lo referido a las reuniones de tipo general como provincial, se tornarán nuestra fuente principal. Entre aquellos aspectos recogidos por estos textos, prestaremos una especial atención a las disputas episcopales por cuestiones territoriales, cuya relectura revelará una nueva perspectiva a la hora de percibir el propio territorio en la Hispania post-imperial. Ello no implicará obviar otras fuentes, como pueden ser aquellos testimonios de carácter epistolar o epigráfico, entre otros. Asimismo, la realidad contemporánea de la Galia merovingia constituirá un recurso comparativo recurrente, dados los recientes avances en la historiografía francesa en torno a la cuestión del espacio diocesano. Por último, las nuevas concepciones de la Geografía Humana también serán un recurso a tener en cuenta para su posible extrapolación al análisis de las diócesis en la Hispania visigoda.

\section{LA DIÓCESIS EPISCOPAL: UNA REALIDAD TERRITORIAL, PERO ANTE TODO SOCIAL}

Como hemos adelantado en la introducción, en la aprehensión de las diócesis episcopales en la Hispania postimperial, y a pesar de lo que se suela afirmar, ${ }^{13}$ no debemos pensar en una correspondencia automática entre los límites del territorium de la ciudad o, en su defecto, de las circunscripciones administrativas romanas con el espacio bajo jurisdicción episcopal. Si fueran tan claros tales límites, no se habría llegado a litigio alguno entre obispos por cuestiones territoriales. De hecho, como tendremos ocasión de comprobar, tales disputas casi nunca se dirimen en torno a fronteras. Por otro lado, debemos de tener en cuenta que la continuidad de los límites urbanos imperiales tampoco estaba garantizada en aquellos momentos. ${ }^{14}$ De todas formas, en el caso de vigencia de las viejas demarcaciones, estas únicamente habrían tenido aplicación en

territorial y a partir de ahí otro de carácter social o, al contrario, primero al establecimiento de un control sobre la población y a partir del mismo una definición territorial del poder.

12 Véase Chouquer 2007: 295-314.

13 García Moreno 1985: 125-126; Barbero de Aguilera 1989: 177; Díaz 2000: 8; Sotomayor Muro 2004a: 288; Kulikowski 2005: 48-49; Martínez Melón 2008: 115-128.

14 En palabras de Y. Codou (2008: 111), «les évêques médiévaux ne peuvent pas se prévaloir de l'héritage des cités antiques pour fonder les limites de leurs diocèses car cet héritage se révèle très théorique». En lo referido a Hispania, Díaz 2008: 123, n. 1. Para mayor profundidad sobre esta cuestión, véase infra. 
un solo ámbito que no tenía que coincidir necesariamente con el eclesiástico. ${ }^{15}$ No hay, por tanto, ningún indicio irrefutable en las fuentes que apunte a una concepción delimitada de las diócesis. En definitiva, la propia pervivencia en el tiempo de las circunscripciones administrativas tradicionales resulta un hecho cuanto menos cuestionable a partir del período post-imperial, siendo especialmente evidente este fenómeno cuando situamos el foco sobre los espacios eclesiásticos. $^{16}$

Por consiguiente, debemos ofrecer nuevas perspectivas a la hora de concebir las realidades territoriales eclesiásticas tardoantiguas y altomedievales. En este sentido, algunos sectores de la historiografía francesa han desarrollado en los últimos años una nueva forma de percibir las diócesis episcopales galas que, desde nuestro modo de ver, se puede extrapolar claramente a sus homólogas y contemporáneas de la península ibérica. Según sus representantes, estas habrían tenido un carácter mucho más social que territorial. ${ }^{17}$ En otras palabras, la influencia episcopal se habría extendido más por factores de relación personal entre la comunidad cristiana que por condicionamientos de tipo territorial, al menos en el período objeto de estudio. Ello ha llevado a algunos de los defensores de esta tendencia a hablar incluso de una "desterritorialización» del concepto de diócesis. Ciertamente, en la línea planteada en su día por

15 Boissellier 2016: 12.

16 Véase Lauwers 2008: 31, quien habla de una debilidad de los cuadros espaciales imperiales; Mazel 2016: 160-181; Zadora-Rio 2016: 345 365. En contra de toda esta argumentación podríamos traer a colación e canon 35 del IV Concilio de Toledo, donde se habla de la integración de toda nueva fundación eclesiástica dentro del «conventus». En el mismo sentido podríamos hablar de la aplicación del susodicho término en el canon 53 del mismo concilio. Conc. IV Tol. (a. 633), cc. 35, 802-808 y 53, 908-913. Ed. G. Martínez Díez y F. Rodríguez, 1992. La colección canónica hispana, V: 232. Madrid: CSIC. De este modo, la palabra "conventus» ha sido considerada por Martínez Díez (1959: 62-63) como sinónimo de «territorio sobre el cual ejerce el obispo sus poderes jurisdiccionales», llevándole a la conclusión, no solo de comprobarse la existencia de unos límites claramente definidos, sino también la imprescriptibilidad o invariabilidad de los mismos. En un sentido similar se manifiestan, Gurt et alii 1993: 168; Sotomayor 2004a: 284, n. 4. Sin embargo, en realidad la atribución de un carácter territorial puede resultar un hecho igualmente cuestionable. En su lugar, su aplicación puede referirse únicamente a la jurisdicción episcopal, es decir, a la dependencia personal de determinado centro o agente religioso a un obispo, sin implicar necesariamente una connotación de carácter territorial. De hecho, en la propia época imperial, donde surgen las realidades conventuales originales, el término no aludía necesariamente a una circunscripción territorial, sino precisamente a una jurisdicción, en este caso de carácter judicial y administrativo, ejercida sobre una suma de comunidades que se sitúan bajo dependencia de una ciudad que actúa en cierta medida como capital. Cf. Le Roux 2014: 113-129. El texto no pretende estipular que una determinada basílica quede bajo jurisdicción diocesana, ello se da por sentado. La centralidad del canon en cuestión la tiene el verbo «pertinebunt» y, en virtud de ello, el texto habría perseguido que las iglesias afectadas quedasen bajo propiedad del obispo que va a ejercer la jurisdicción sobre la misma, presumiblemente aquel que la consagra, y no de otra persona. En realidad, el canon 35 únicamente estaría reafirmando el c. 19 del III Concilio de Toledo (Conc. III Tol. a. 589, c. 19, 885-890) al remarcar, no tanto que la iglesia quede bajo la jurisdicción de un obispo, lo cual se da por supuesto, sino que esta, y por extensión sus propiedades, permanezcan bajo propiedad episcopal. Para un uso similar del término «conventus», Conc. $X$ Tol. (a. 656), «Item decretum pro Potamio episcopo», 264-267. Para un significado diferente del mismo, aunque aplicado a una casuística extra-eclesiástica, Díaz 1993: 215.

17 Aupest-Conduché 1978: 390; Gauthier 2000: 203; Lauwers 2008: 23-68; Lunven 2014; Mazel 2016. la Geografía Humana, consideramos que en realidad la instauración de un dominio territorial se producía a partir de la imposición del poder sobre un cuerpo social concreto y no al revés. ${ }^{18}$ Aplicado al caso de las diócesis episcopales postimperiales y haciéndonos eco de las palabras de F. Mazel, "la paroisse épiscopale - en el sentido de diócesis - apparut de plus en plus comme un conglomérat mouvant de personnes et de lieux soumis à l'autorité plus o moins effective de l'évêque». ${ }^{19}$

Aun aceptando esta consideración más social que territorial de las diócesis, estimamos excesiva la desconsideración hacia el papel del propio territorio en todo el proceso de construcción de las mismas. De esta manera, y apoyándonos de nuevo en presupuestos geográficos, toda acción social se desarrolla en un marco espacial concreto más o menos delimitado, en definitiva, en un territorio, escenario indispensable del poder y de todas las relaciones sociales. ${ }^{20}$ De hecho, la territorialidad sería la primera plasmación espacial del ejercicio del poder social. ${ }^{21}$ El territorio surgiría, pues, en el momento en el que se establecen relaciones sociales -entre las que incluimos las de poder - en un espacio determinado. En otras palabras, «territories are the effect of the material inscription of social relationships».22 Todas estas ideas son claramente aplicables al caso de las diócesis episcopales, cuya existencia vendría intrínsecamente ligada a la imposición de relaciones de poder de carácter espacial por parte del obispo. ${ }^{23}$ De forma paralela a la extensión de su control social, los obispos habrían procurado asegurarse una obtención de riquezas constante a través de la apropiación de propiedades fundiarias y su explotación directa o indirecta, siendo aquí donde también debemos entender la importancia del territorio y el interés episcopal por controlarlo y apuntalar la propiedad sobre el mismo. ${ }^{24}$ Esto ayudará a entender más adelante las disputas episcopales por cuestiones territoriales. Sin embargo, y aunque parezca una obviedad, ese dominio sobre el espacio únicamente podía asegurarse si previamente se había obtenido un control sobre el cuerpo social en él radicado y destinado a su explotación.

De esta manera, dada la centralidad del establecimiento de relaciones personales a la hora de extender el ámbito de influencia episcopal, se volvía de vital importancia para el obispo conseguir la adhesión y lealtad personales del clero diocesano. A fin de cuentas, serían estos agentes eclesiásticos los que le representarían en cada comunidad y proyectarían su autoridad sobre el territorio, ${ }^{25}$ al mismo tiempo que serían los encargados de vigilar y administrar

18 Cf. Gottmann 1973: 3-4; Raffestin 1980: 3-4; Sassen 2006: 40-41.

19 Mazel 2016: 156.

20 Tal y como pone de manifiesto S. Sassen (2006: 33), «although exclusive territorial authority was not the defining trait of the political logic, social and political organization forms had territorial insertions». En unos términos similares se manifiestan: Gottmann 1973: 60; Brighenti 2010: 52-72.

21 Sack 1986: 5, 26. Entre la historiografía, defiende esta idea Castellanos 2006: 141-163.

22 Brighenti 2010: 56-60.

23 Véase Guerreau 1996: 85-101.

24 Sobre el interés episcopal por la obtención y control de las riquezas, véase Brown 2012: 481-502. Véase también Wood 2013: 37-73.

25 Sobre el clero que actuaba sobre tales comunidades, Fernández Alonso 1955: 207-209. 
las propiedades eclesiásticas en la región. Para asegurarse de que así fuera, lo lógico era que el presbítero fuera de la elección episcopal, al mismo tiempo que se escogía un candidato con el carisma y el prestigio religioso mínimos para generar aceptación entre la población y aglutinar en torno a sí a la comunidad sobre la que profesaría su acción pastoral. Así se entendería la designación de Emiliano por parte de Dídimo de Tarazona, a quien el obispo habría instrumentalizado para extender su influencia en una región periférica de su diócesis. ${ }^{26}$ Sin embargo, la elección de estos personajes ascéticos también habría supuesto un peligro para el propio poder episcopal, dado que la radicalidad de estos y su propio carisma suponían en sí mismas una amenaza a la autoridad religiosa del obispo. ${ }^{27}$ Con todo, parece ser que los prelados preferían tener a estos individuos de su parte, para controlarlos mínimamente, a que escaparan completamente de su control.

En caso de no gozar de la adhesión personal del sacerdote de turno, el obispo podía ver amenazada su autoridad sobre una determinada comunidad. Es decir, un presbítero podía en cualquier momento acercarse a un prelado vecino, abriéndole así las puertas a un futurible control de su comunidad de feligreses. Es en ese sentido en el que debemos entender algunas medidas conciliares dirigidas a controlar la elección y acción de los clérigos. ${ }^{28}$ Uno de los casos más tempranos lo encontramos recogido en las cartas del obispo Montano de Toledo y los intentos de este por controlar la actividad pastoral y litúrgica de los presbíteros de la diócesis de Palencia. ${ }^{29}$ Especialmente llamativo es el canon 2 del II Concilio de Toledo del 531, donde se prohíbe a todo clérigo abandonar su iglesia y pasar a la diócesis de otro obispo. ${ }^{30}$ Tales medidas en última instancia confirman ese carácter personal de la jurisdicción episcopal sobre su clero y, por tanto, la debilidad del fundamento territorial de su autoridad. Las diócesis se volvían, pues, realidades fluctuantes, ${ }^{31}$ condicionadas por cada coyuntura, al tratarse de espacios donde distintos agentes - en este caso los obispos - confluían y pugnaban por extender sus redes de influencia. ${ }^{32}$ Por consiguiente, en este escenario dominado por las relaciones sociales, en las que el poder se ejercía no tanto en función de criterios jurídicos, institucionales o territoriales como a partir del establecimiento de vínculos personales

26 Braul., Vita Sancti Aemiliani, 5. Ed. J. Oroz, 1978. "Sancti Bravlionis Caesaravgvstani episcopi. Vita Sancti Aemiliani». Perficit 9/119-120: 191-192. Cf. Martin 2007: 214.

27 Jussen 2001: 166.

28 Por ejemplo, Conc. II Tol. (a. 531), cc. 2-4, 49-78; Conc. Ilerd. (a. 546), c. 12, 116-122; Conc. Vallet. (a. 549), cc. 5-6, 92-104. Ed. G. Martínez Díez y F. Rodríguez, 1984. La colección canónica hispana, IV: 305, 319320; 349-352. Madrid: CSIC. Conc. III Tol. (a. 589), c. 5, 759-772; Conc. IV Tol. (a. 633), cc. 18, 641-647; 20, 688-696; 23, 717-721; 26-27, 741750; 39-47, 833-877; 73-74, 70-90; Conc. VI Tol. (a. 638), cc. 4-6, 150-181; Conc. VIII Tol. (a. 653) cc. 5-8, 557-650; Conc. II Hisp. (a. 619) cc. 3-5; Conc. Emer. (a. 666), cc. 9-12, 18. Ed. J. Vives, 1963. Concilios visigóticos e hispano-romanos: 164-166, 332-334, 338. Barcelona-Madrid: CSIC.

29 Conc. II Tol. (a. 531), 132-234.

30 Conc. II Tol. (a. 531), c. 2, 49-55. Otros casos similares en Conc. II Hisp. (a. 619), c. 3; Conc. XIII Tol. (a. 683), c. 11, 605-653. Ed. G. Martínez Díez y F. Rodríguez, 2002. La colección canónica hispana, VI: 252-255. Madrid: CSIC.

31 En contra de tales postulados, Martin 2003: 79, quien aboga por la inmutabilidad de las diócesis episcopales.

32 Boissellier 2016: 12; Mazel 2016: 156-159, 182, 186. de dominación sobre la sociedad, ${ }^{33}$ nos resulta difícil concebir la diócesis como un ente territorialmente definido, con demarcaciones claramente establecidas, conocidas y reconocidas por todos. Si la jurisdicción diocesana hubiese sido una realidad territorialmente tan definida e inmutable, no se entenderían las resoluciones conciliares del IV Concilio de Toledo, donde se establece que todo aquel obispo que haya poseído durante treinta años una iglesia previamente bajo control del titular de otra diócesis, tendría derecho a mantenerla bajo su jurisdicción de forma definitiva en caso de no constar reclamación alguna sobre ella por parte de su posesor original. ${ }^{34}$

Atendiendo a esta reformulación más o menos continua del espacio de influencia del obispo, se estima lógico que no haya una correspondencia absoluta, y posiblemente ni aproximada, entre las diócesis y las civitates, ya no solo en la extensión de sus correspondientes territoria, sino también en su propio número y localización..$^{35}$ De esta manera, es posible que una diócesis tuviese bajo su jurisdicción uno o varios núcleos urbanos carentes de sede episcopal. No se advierte, pues, una correspondencia entre política religiosa y administración civil. En virtud de ello, la transformación del territorio eclesiástico no tenía que implicar necesariamente una reorganización administrativa, ${ }^{36}$ ya que cada esfera de actuación se desarrollaba en función de sus propias dinámicas y objetivos.

Sobre las formas que podía tomar la territorialidad diocesana, esta se habría percibido con unos límites no muy claros, también en la Hispania post-imperial. ${ }^{37}$ La delimitación del territorio no tiene que ser una condición imprescindible para su construcción, mucho menos desde la perspectiva social que priorizamos en este trabajo. ${ }^{38}$ Clara prueba de ello es la ausencia completa en las fuentes eclesiásticas de menciones explícitas a los límites diocesanos. Esta relativización, o incluso relegación, de la delimitación territorial como método de definición de la jurisdicción diocesana a favor del factor humano queda claramente de manifiesto en los escritos del papa Gelasio I. ${ }^{39}$ De hecho, dadas estas dinámicas formativas y de desarrollo de las diócesis, estas realidades territoriales podían adquirir un carácter discontinuo, según han planteado algunos autores en otros marcos geográfi$\cos .^{40}$ Podríamos estar así ante territorios sin continuidad en el espacio, con una jurisdicción limitada a aquellas zonas

33 Sobre la centralidad de las relaciones personales en este período, véase Althoff 2004; Wickham 2005; Halsall 2007, entre otros. Para el caso visigodo, Barbero y Vigil 1978; Wood 1999: 191-223, entre otros.

34 Conc. IV Tol. (a. 633), c. 34, 802-807.

35 Un fenómeno similar se desarrollaría en la Galia. Cf. AupestConduché 1978: 390; Mériaux 2008: 119-142, quien pone como ejemplo los casos de Cambrai y Tournai, que habrían sustituido a las precedentes sedes de Bavay y Cassel como lugares centrales; Codou 2008: 195-196, quien presenta una casuística centrada en la Provenza.

36 Cf. Schneider 2008: 69-96.

37 Jones 1999: 70.

38 Profundiza en esta concepción del territorio, Painter 2009: 57-66. Un punto de vista alternativo en Mazel 2013, quien considera que un espacio se territorializa únicamente cuando se le dota de unos límites lineares.

39 Gel. Frag. 17 y 19, A. Thiel. 1868, Epistolae romanorum pontificum genuinae, I: 492-494. Brunsberg: E. Peter. Véase al respecto Lauwers 2008: 31-32; Mazel 2016: 100-101.

40 Cf. Moulet 2017: 45-59. En un sentido general, Guerreau 1996: 85-101; Cohen et alii 2014: 1-20. 
donde tuviese alcance la influencia episcopal. ${ }^{41}$ De hecho, en la mayoría de las ocasiones el dominio episcopal habría presentado su fortaleza en las ciudades y en su entorno más inmediato, difuminándose en los ámbitos rurales; ${ }^{42}$ aunque esto último habría dependido en última instancia de la propia capacidad de cada obispo para mantener controlado al conjunto de clérigos bajo su directa dependencia. Es posible que los propios obispos no hubiesen tenido en muchos casos unas amplias expectativas de dominio del territorio, lo que, unido también al propio carácter fluctuante de su dominación, explicaría en parte el alcance limitado de su jurisdicción, especialmente en las periferias de la diócesis. Por todo ello es por lo que preferimos hablar, en la línea planteada por I. Martín Viso, de una territorialidad difusa de las realidades diocesanas. ${ }^{43}$

EL PAPEL DE LAS IGLESIAS RURALES EN LA IMPLANTACIÓN TERRITORIAL DEL PODER EPISCOPAL

Obviamente dicha percepción del espacio vendrá fuertemente influida por la forma en la que el propio territorio se articula. Ante la ausencia de unos límites jurisdiccionales claramente definidos para el caso de las diócesis, como hemos venido planteando hasta ahora, se requerían otras formas de marcar y proyectar el poder del obispo. Tal y como infirió J. Fernández Alonso a partir del Parroquial Suevo, "llama en seguida la atención que para describir la extensión de una diócesis no se señalen sus límites, sino el número de sus parroquias con los nombres respectivos", para concluir defendiendo que «más que por límites territoriales claramente determinados, quedaría concretada la extensión de una diócesis por las parroquias que por iniciativa propia y con la colaboración de su clero estableciera en las regiones vecinas el obispo respectivo». ${ }^{44}$ ¿Es extrapolable este modelo al caso de las diócesis hispanovisigodas? Creemos considerar que así es. De este modo, estimamos que el elemento central en la definición territorial de las diócesis era el despliegue espacial de una red más o menos densa de lugares centrales bajo dependencia episcopal, ${ }^{45}$ fueran estos las propias sedes episcopales, monasterios 0 , sobre todo, iglesias rurales. Resulta muy reveladora al respecto la siguiente afirmación de C. Martin: «De la même manière que les armées ne contrôlent jamais véritablement tout l'espace rural, mais les îles fortifiées que le parsèment, cités et castra, de même l'évêque maîtrise surtout les points forts, au sens non militaire, que sont les églises et

\footnotetext{
41 Rechazamos así la postura de Ripoll y Velázquez 1999: 243 al considerar que las propias iglesias rurales delimitaban sus áreas de influencia por medio de termini.

42 Martín Viso 1999: 164.

43 Ibídem: 160.

44 Fernández Alonso 1955: 203-205.

45 Cf. Le Jan 2007: 403; Harrison 2001: 83-94. Sobre el papel de los lugares centrales en la articulación territorial general del espacio y su tipología, véase Martínez Jiménez y Tejerizo García 2015: 82-86. Este mecanismo de implantación territorial es lo que Morsel (2006b: 97) ha denominado «appropriation polaire» del espacio, es decir, a través de la apropiación de un punto concreto de carácter central se concentraría la energía de implantación sobre el conjunto del territorio. Remarcando tal funcionalidad para las iglesias rurales, Sánchez Pardo y Shapland 2015:
} 1-33. les monastères». ${ }^{46}$ De esta manera, la erección o absorción de una iglesia determinada por parte del obispo supondría también la inclusión en la jurisdicción episcopal del territorio circundante a dicho centro. ${ }^{47}$ Ello tiene como consecuencia que sea para nosotros imposible tener una percepción más o menos aproximada del territorio controlado por un obispo determinado. ${ }^{48}$ Por lo tanto, la diócesis, como ente territorial, vendría conformada ante todo por la suma de lugares de culto bajo control episcopal. ${ }^{49}$ De hecho, la propia actividad edilicia religiosa de los obispos era remarcada en los escritos hagiográficos como una de las más destacadas de su ministerio, como fuente de prestigio. ${ }^{50}$

La implantación de dichos lugares centrales tendría el objetivo fundamental de controlar ese espacio y sus habitantes, ya no solo en términos socio-políticos, sino también ideológicos o económicos. ${ }^{51}$ Aplicando la terminología derivada de la Antropología, podríamos definir a las iglesias también como "centros activos del orden social», ya que es en ellas donde se concentraban los actos de la vida religiosa y social más importantes de la comunidad, ${ }^{52}$ lo que permitía al obispo tener un grado de penetración muy intenso en el ámbito rural..$^{53}$ De esta manera, el espacio de la diócesis no podía imponerse sin más como una circunscripción territorial más, sino que necesitaba un previo y lento proceso de implantación de la influencia episcopal a través de la construcción de centros eclesiásticos en el mundo rural con los que asegurarse el control del culto y de la comunidad cristiana en esos territorios. Obviamente, a la hora de implantar este tipo de centros el obispo requería la aquiescencia de las comunidades donde estos se fuesen a erigir. De especial relevancia habría sido la consecución de la aceptación de los agentes locales más poderosos, lo que exigió una labor de negociación del obispo de turno con estas élites. ${ }^{54}$ Debemos entender que este factor habría influido en la dispersión desigual que adquirió la distribución espacial de este tipo de lugares centrales bajo dependencia episcopal. ${ }^{55}$

La red episcopal de iglesias rurales empezó a extenderse desde época bastante temprana. El propio Concilio I de Toledo hace referencia a las basílicas situadas «in castella, aut vico aut villa», ${ }^{56}$ por lo que es posible que el proceso se hubiese iniciado en el siglo $I V,{ }^{57}$ teniendo continuidad, con mayor intensidad incluso, durante los dos siglos

\footnotetext{
46 Martin 2007: 211. En lo relativo al caso galo, se manifiesta en términos similares Mériaux 2008: 122.

47 Sotomayor Muro 2004a: 288.

48 Mériaux 2008: 122.

49 Mazel 2016: 187.

50 Velázquez 2007: 264. Sobre las posibles circunstancias que podían llevar a la erección de una iglesia en un lugar determinado, Fletcher 1998: 98.

51 Brogiolo y Chavarría Arnau 2008: 11.

52 Geertz 1994: 148.

53 Ello provocará que la propia monarquía se interese por entrar en relación con los obispos, instrumentalizado así las estructuras territoriales diocesanas en pro de los estrictos intereses regios. Un caso de estudio aplicado a la realidad merovingia en Poveda Arias 2019.

54 Sánchez Pardo 2016: 373.

55 Una perspectiva regional en Sánchez Pardo 2014: 439-480.

56 Conc. I Tolet. (a. 400), c. 5, 89-93. La mención a tales núcleos de distinto tipo nos está poniendo en evidencia una adaptación del proceso formativo de las diócesis al poblamiento y a la organización del espacio, tal y como ha sido planteado para el caso suevo; Díaz 2011: 204.

57 Ripoll y Velázquez 1999: 101-165.
} 
siguientes..$^{58}$ En algunas regiones de la Península la densidad de este tipo de construcciones debía de ser muy alta, en concreto en la Lusitania. En el Concilio de Mérida del 666 se exige que un mismo presbítero con varias iglesias a su cargo, suponemos que también rurales, imparta misa en cada una de ellas todos los domingos..$^{59}$ Este dato estaría indicando que en muy pocos kilómetros a la redonda, los necesarios para darle tiempo al sacerdote a desempeñar su ministerio en un mismo día, estarían repartidos varios centros de culto. De todas formas, no sería hasta a partir del siglo VI cuando podríamos hablar de una fuerte influencia episcopal en el rusticum. ${ }^{60}$ Hasta entonces lo más posible es que este último hubiera gozado de una amplia independencia frente al poder del obispo. ${ }^{61} \mathrm{~A}$ todo ello debemos sumarle el desarrollo paralelo de construcción de iglesias por iniciativa privada que, aunque favorecía la cristianización del campo, se trataba de un proceso que inicialmente escapaba al control del obispo. ${ }^{62}$ De hecho, parece ser que el grueso de las iniciativas fundacionales durante los siglos IV y $V$ fueron protagonizadas por las propias élites rurales, mientras que los obispos tenían en estos momentos la ciudad como marco de acción preferente. ${ }^{63}$ Con todo, lo cierto es que para principios del siglo VI la red de iglesias bajo dependencia episcopal debía de ser importante. Así es como debemos entender las alusiones a las basílicas rurales en el canon 13 del Concilio de Tarragona, en el que se requiere a los obispos asistentes a futuros sínodos que acudan acompañados de algunos de los presbíteros radicados en las iglesias rurales bajo su dependencia. ${ }^{64} \mathrm{~A}$ esto se le unen los continuos intentos episcopales a lo largo de todo el período visigodo dirigidos a controlar todas las acciones fundacionales paralelas que se desarrollaban al margen de su autoridad, ${ }^{65}$ reafirmando así su poder sobre el territorio. En concreto, los obispos habrían procurado arrogarse la exclusividad en la consagración de iglesias, fueran estas urbanas o rurales, así como la supervisión de la actividad pastoral y litúrgica de

58 Sotomayor Muro 2004b: 539; Brogiolo y Chavarría Arnau 2008: 12; Chavarría Arnau 2010: 160-174. En algunos casos, como se ha estimado para el caso galaico, el origen de todas estas iglesias rurales habría tenido lugar a mediados del siglo VI. Cf. Sánchez Pardo 2013: 11-50.

59 Conc. Emer. (a. 666), c. 18.

60 Fernández 2016: 518. Para un estudio de caso, Sánchez Pardo 2010: 149-170.

61 Díaz 2000: 23-24.

62 Sobre el fenómeno fundacional de iglesias privadas, véase Torres López 1925: 402-461; Bidagor 1933; Díaz 1986: 297-303; Wood 2008; Chavarría Arnau 2010: 160-174, quien aporta más referencias relativas a este fenómeno.

63 Bowes 2008: 125-188. Véase también Cantino Wataghin 2013: 189-204. De todas formas, en todo este panorama debemos advertir una diversidad regional, apreciando en algunas zonas, como la Submeseta Norte, donde la fundación de iglesias rurales por iniciativa de las élites fue un fenómeno más aislado. Arce Sainz y Moreno Martín 2012: 106.

64 Conc. Tarrac. (a. 516), c. 13.

65 Conc. III Tol. (a. 589) cc. 15, 621-628 y 19, 648-687; Conc. IV Tol. (a. 633) c. 35, 808-811. Wood 2008: 18. Hasta esos momentos, parece ser que las propias élites habrían actuado como obispos in absentia. Bowes 2008: 127. De todas formas, a pesar de estos intentos de control y de lo defendido por algunos autores, en ningún momento podemos llegar a negar la existencia de tales iglesias privadas. Cf. Martínez Díez 1959: 71-79; Sotomayor Muro 2004b: 531. De hecho, a partir de la segunda mitad del siglo VII, especialmente, este tipo de iniciativas privadas adquirirá mayor importancia e incluso un amparo político superior al de los obispos para mantener bajo control este fenómeno. Cf. Chavarría Arnau 2010: 166-167; Wood 2014: 895-912. las mismas. Finalmente, también habrían intentado hacerse con la propiedad de tales iglesias y el patrimonio asociado a ellas. ${ }^{66} \mathrm{Al}$ final, para el siglo VI los obispos se habían convertido en las autoridades con mayor grado de influencia y penetración sobre el territorio hispano, fuera del alcance de cualquier otra instancia de poder, incluida la propia monarquía visigoda.

Respecto a la terminología aplicada a estos centros eclesiásticos rurales, algunos autores aplican el término de "parroquia», empleado asimismo para aludir a las zonas rurales circundantes a los mismos. ${ }^{67}$ Las fuentes recurren a este vocablo, pero la mayor parte de la historiografía prefiere emplearlo únicamente como sinónimo de diócesis, siendo en ese sentido en el que tendría que entenderse la alusión a ecclesiae parrociales. ${ }^{68}$ En un punto intermedio se situaría G. Martínez Díez, quien advierte una aplicación indistinta del término parrochia para hacer referencia a la comunidad de fieles dependiente de un obispo y a las congregaciones menores bajo responsabilidad de un presbítero. ${ }^{69}$ Por nuestra parte, dada la falta de acuerdo entre los especialistas, emplearemos el calificativo de «iglesias rurales», mucho menos problemático. ${ }^{70}$ Parece ser, además, que las pretendidas parroquias aparecen referenciadas con el término "ecclesiae» en el propio Parrochiale Suevum, cuyo título original, si lo tuvo, habría sido diferente y, por tanto, no habría hecho alusión a las realidades parroquiales. ${ }^{71} \mathrm{De}$ esta manera, el problema terminológico ha llevado a atribuir a estas basílicas rurales un ámbito de actuación territorial claramente delimitado, adelantando así en el tiempo las dinámicas parroquiales posteriores a unas iglesias que, como acabamos de exponer, ni siquiera habrían sido aludidas de esta manera. Sin embargo, en la línea apuntada por E. Zadora-Rio, no debemos hacer una extrapolación del momento fundacional de una determinada iglesia y del proceso de cristianización del campo con la formación del sistema parroquial. ${ }^{72}$

En resumidas cuentas, no hay razón para pensar que la apropiación de un territorio determinado deriva obligatoriamente de una delimitación lineal o natural del mismo. ${ }^{73}$

66 Conc. III Tol. (a. 589) cc. 2, 365-376; 9, 520-529; 19, 648-687; Conc. II Hisp. (a. 619) c. 7; Conc. IV Tol. (a. 633) cc. 2, 365-376; 5-18, 440647; 26, 341-346; 33-34, 785-807; 37, 818-823; 67 24-33; Conc. VI Tol. (a. 638), c. 5, 161-170; Conc. IX Tol. (a. 655), cc. 1, 60-86; 3-9, 107-198; Conc. Emer. (a. 666), c. 2; Conc. XI Tol. (a. 675), c. 3, 309-421; Conc. II Bracar. (a. 675), cc. 1-2. Cf. Fernández Alonso 1955: 215-224; Martínez Díez 1959: 71-79; Sotomayor Muro 1982: 649.

67 Ripoll y Velázquez 1999: 111-113, aunque las autoras reconocen que la misma palabra tiene la acepción de diócesis. Las realidades diocesanas también suelen ser referenciadas en las fuentes, especialmente en las de carácter legal, con el término territorium; Díaz 2000: 23-24, n. 94.

68 Cf. Sotomayor Muro 2004a: 283-297. Véase también Pietri 1997: 497-499; Delaplace 2002: 15-16.

69 Martínez Díez 1959: 54.

70 Incluso el propio término «diocesis» puede adquirir un sentido polisémico. Cf. Mazel 2016: 95-96.

71 Díaz 1998: 36-38; Sánchez Pardo 2014: 439-480.

72 Zadora-Rio 2016: 345-365. Negando también esta atribución «territorial» al término parrochia, Lauwers 2005: 11-32. Para un caso de estudio extrapeninsular donde se percibe claramente esta distinción temporal entre iglesia rural y parroquia, Lunven 2016: 325-344, esp. 338-343.

73 Tales presupuestos han Ilevado a algunos especialistas a reconstruir los límites diocesanos, generalmente a partir de argumentos ex silentio sustentados en la presencia de accidentes geográficos o de antiguas circunscripciones romanas de las que no tenemos constancia para 
Puede haber otros mecanismos para la consecución de este objetivo. ${ }^{74}$ De esta manera, a pesar de que la historiografía española suela referirse a las diócesis como entidades territoriales claramente definidas, consideramos que la jurisdicción diocesana se construía ante todo a través del establecimiento de relaciones sociales de poder en un espacio determinado. Dentro de este esquema, la norma canónica que exige a los obispos visitar anualmente las distintas ecclesiae de la diócesis habría estado destinada precisamente a reforzar tales lazos con las comunidades, constituyendo en sí mismo un mecanismo de apropiación y dominación territoriales. ${ }^{75}$ Por otra parte, dicho control habría quedado fijado y simbolizado con la percepción episcopal de un tercio de las rentas de estas iglesias. Por lo tanto, la construcción o absorción de iglesias rurales por iniciativa de los propios obispos habría tenido también una implicación económica. ${ }^{76} \mathrm{~A}$ través de esas rentas, el poder episcopal se aseguraba unos ingresos con los que continuar con su actividad fundacional y, por extensión, con los que seguir extendiendo sus redes de influencia sobre el territorio extraurbano y sus habitantes. Sin embargo, el acto fundacional por sí solo no habría bastado para reproducir su dominación en el tiempo. Para ello el obispo se habría visto forzado a mostrar un flujo regular de generosidad hacia su comunidad de fieles, especialmente aquella radicada en el ámbito rural. ${ }^{77}$ En definitiva, son todas estas tareas, en su conjunto, junto a la exclusividad en la consagración de basílicas, las que habrían remarcado sobre el terreno la posición de superioridad eclesiástica de la autoridad episcopal. ${ }^{78}$

La propia epigrafía conservada, la evidencia más numerosa para conocer este fenómeno, ${ }^{79}$ resulta muy reveladora

estas cronologías. Para algunos ejemplos, véase García Moreno 2007: 452-453; Martínez Melón 2008: 115-128; Lorenzo de San Román 2016: 291-297, entre otros.

74 Una propuesta tipológica de tales mecanismos en Morsel 2006b: 89-104.

75 Conc. Tarrac. (a. 516), c. 8, 96-104; Conc. IV Tol. (a. 633), c. 36 808-811. Sería lo que Morsel 2006b: 99 ha denominado un mecanismo de "apropiación areolar», que el autor define de la siguiente manera: "cette appropriation se réalise principalement sous la forme d'une déambulation, plus ou moins aléatoire, entre divers points de l'espace concerné, accomplie soit par l'ensemble de la communauté considérée, soit par leurs représentants». Al mismo tiempo, dicha visita permitía al obispo supervisar el funcionamiento y la situación de tales iglesias. Fernández Alonso 1955: 224-228. Desde un plano general, remarcan la importancia de la visita del obispo a los centros rurales bajo su dependencia, Lauwers 2008: 25-26; Mazel 2016: 119-126.

76 Conc. Tarrac. (a. 516), c. 8, 96-104; Conc. IV Tol. (a. 633), c. 33, 785-801; Conc. IX Tol. (a. 655), c. 6, 151-159; Conc. Emer. (a. 666), cc. 14 y 16; Conc. XVI Tol. (a. 693) c. 5. De hecho, algunos especialistas han priorizado este aspecto económico como motor a la hora de implantar iglesias en el territorio por parte del obispo, hasta el punto de negar cualquier otro tipo de motivación en la fundación de estos centros. $C f$. Utrero Agudo y Moreno Martín 2015: 97-131.

77 Martin 2007: 210-211. Véase también Fuentes Hinojo 2008: 315-344.

78 Martínez Díez 1959: 69; Ubric Rabaneda 2004: 51. Tal y como aplica Wood 2014: 897 para los casos itálico y galo, «the strength of the bishop's position, such as it was, lay in the fact that a founder would want his church consecrated and would know that only a bishop had the sacramental power to do this».

79 Se trataría generalmente de inscripciones asociadas a restos arquitectónicos. La práctica totalidad de las mismas se encuentra datada en el siglo VII. Véase Gimeno Pascual 2009: 31-44; Rico Camps 2009: 7-53. a la hora de aproximarnos a las dinámicas de implantación de las redes de influencia episcopales sobre el territorio. También disponemos de algunos testimonios documentales, ciertamente bastante puntuales y parcos en información. De hecho, como balance general, debemos reconocer que la casuística conocida sobre fundaciones rurales es bastante escasa. ${ }^{80}$ Tal y como se ha aducido para el caso de la Galia merovingia y carolingia, es posible que esta carencia testimonial apunte al carácter excepcional que pudo tomar esta práctica en Hispania, al menos en algunas regiones. ${ }^{81}$ Por ejemplo, para la mitad septentrional de la Península disponemos de un número extremadamente pequeño de evidencias que nos ayuden a rastrear la acción episcopal en el ámbito rural. Como caso más paradigmático contamos con el epígrafe fundacional de la iglesia de Santa María de Mijangos, para nada exento de problemas. En él se evidencia la actividad consagratoria de un obispo, lo más seguro el de Oca, cuya acción habría estado en este caso auspiciada por el propio rey, posiblemente Recaredo. ${ }^{82}$ También en el sector septentrional, Valerio del Bierzo nos transmite la consagración de una iglesia de manos del obispo Aurelio de Astorga entre los años 681 y $693 .^{83}$ En el ámbito lusitano las fuentes destacan la consagración de basílicas por parte de los obispos emeritenses. Las VSPE ponen de manifiesto, por ejemplo, la labor fundacional del célebre Masona de Mérida. ${ }^{84}$ Para el pontificado de Oroncio de Mérida tenemos constancia de la consagración de una iglesia dedicada a Santa María (Ibahernando) en torno al año $635 .{ }^{85}$ En el sector levantino, concretamente en la actual localidad de Cehegín (Murcia), se han hallado unas inscripciones, para nada exentas de problemas, que revelan la acción edilicia de los obispos Vitalis y Acrusmino de Bigastri, ${ }^{86}$ desarrollada aparentemente en algún momento del siglo VI o principios del VII. ${ }^{87}$ También en Levante, sabemos de iniciativas fundacionales similares para el episcopado de Atanasio de Játiva. ${ }^{88}$

Sin embargo, la región más rica en este tipo de testimonios y la que nos permite conocer en mayor medida las dinámicas de los obispos en la construcción de sus respectivas diócesis es sin lugar a dudas la Bética. ${ }^{89}$ Uno de los casos más elocuentes al respecto es el de la fundación de la iglesia de Nativola por el inlustris Gudiliuva, consagrada por el obispo Paulo de Acci a petición de su fundador..$^{90} \mathrm{La}$ basílica en cuestión se dedicó a san Esteban y se ha localizado en las proximidades de la ciudad de Granada, incluso

80 Una casuística muy completa de las fundaciones episcopales en Utrero Agudo y Moreno Martín 2015: 97-131.

81 Mazel 2016: 118.

82 Cf. Lecanda 1994: 173-196. Sobre la problemática que gira en torno a la sede de Oca, véase Larrañaga Elorza 1989: 171-190; Martín Viso 1999: 151-190.

83 Val. Bergid., Replicatio Sermonvm a prima conversione, 16. Ed. M. C. Díaz y Díaz, 2006. Valerio del Bierzo. Su persona. Su obra. 299.

84 VSPE, V, 3, 8-12. Ed. A. Maya Sánchez, 1992. Vitas Sanctorvm Patrvm Emeretensivm, CC, Series Latina, 116: 50. Turnhout: Brepols.

85 Cf. Duval 1993: 186; Utrero Agudo y Moreno Martín 2015: 122-123.

86 ICERV, 318-319. Duval 1993: 188, 190.

87 Espluga Corbalán et alii 1984: 69-70.

88 ICERV, 317. Sobre su problemática, Duval 1993: 191, n. 161.

89 Para una casuística completa, cf. Castillo Maldonado 2005: 335350. Véase también Sánchez Ramos et alii 2015: 221-265.

90 ICERV, 303; CIL A, IV, 38. Se ha cuestionado el carácter estrictamente privado de esta fundación; Velázquez 2007: 262. 
en la colina de la Alhambra, ${ }^{91}$ opción que consideramos la más plausible. Se ha pensado que la intervención del titular accitano a las puertas mismas de la sede iliberritana habría obedecido a una situación de vacancia de esta última. ${ }^{92}$ Sin negar del todo esta posibilidad, ${ }^{93}$ lo que se infiere a través de esta inscripción es la intervención de obispos en territorios sobre los que en principio no deberían tener jurisdicción alguna. De este modo, entendemos la consagración de la iglesia de Natívola como una muestra de las estrechas relaciones personales entabladas entre el obispo accitano y el inlustris Gudiliuva, todo ello en detrimento de los intereses del obispo de lliberris. Tendríamos así una prueba de la centralidad del factor social a la hora de extender la jurisdicción diocesana de un obispo determinado.

Unos testimonios más tardíos, pero igualmente interesantes, son las inscripciones relativas a la dedicación de iglesias por parte del obispo Pimenio de Assidonia durante el segundo tercio del siglo VII. ${ }^{94}$ La más interesante de todas, a nuestro modo de ver, es aquella referida a la consagración de una basílica en el lugar de Salpensa, situado en las cercanías de la actual Utrera. Por tanto, la acción fundacional se habría realizado en una zona excesivamente septentrional y cercana a la sede metropolitana de Sevilla. Sobre las posibles explicaciones a esta consagración, la opción de la vacancia temporal de la sede hispalense se nos torna ciertamente improbable atendiendo a la mayor cercanía de la sede de Italica frente a la asidonense. De este modo, es posible que estemos ante una intromisión del titular de Asidona en el ámbito natural de influencia del obispo metropolitano..$^{95}$ En cierta manera tales movimientos estarían señalando la pérdida paulatina de poder del obispo metropolitano de Sevilla, situación que creemos que se produjo a raíz de la muerte de Isidoro, abriendo así un contexto favorable a la acción del enérgico Pimenio. No descartamos que la actuación del asidonense hubiese generado una disputa con el metropolitano hispalense de turno, Honorato. Ahora bien, su invisibilidad en las fuentes, en especial la inexistencia de un concilio donde se escenificase y se resolviera el potencial conflicto puede apuntar, bien a una resolución extraoficial del mismo, bien a la resignación del obispo metropolitano.

Es quizás dentro de la competencia entre Pimenio y la sede hispalense en la que debemos enmarcar, en torno al 636-641, la consagración por parte de Honorato de Sevilla de una iglesia martirial, radicada en la localidad actual de Dos Hermanas y por lo tanto en las proximidades del área donde sabemos que el obispo de Asidona estaba actuando.

91 García Moreno 1985: 143. También se inclinan por esta opción: Canto de Gregorio 1995: 343-346; Castillo Maldonado 2005: 341, n. 36. En contra: Duval 1991: 815-817; Carbonell i Manils y Gimeno Pascual 2010: 244-245.

92 García Moreno 1985: 127; Castillo Maldonado 2005: 341.

93 Al fin y al cabo, la vacancia episcopal suponía un riesgo para la diócesis afectada, puesto que abría la puerta al intervencionismo de obispos extranjeros, cuya acción podía traer consecuencias irreversibles; Mazel 2016: 215-221.

94 Una en Barbate en el 644 (ICERV, 305); otra en Salpensa en el 648 (ICERV, 306; CIL A, II-3, 959). Aparte de estas iglesias rurales, también tenemos testimoniada la consagración por parte del mismo obispo de una basílica urbana en el 630. ICERV, 304. Cf. Sotomayor Muro 2002: 483-484; Utrero Agudo y Moreno Martín 2015: 123-125.

95 En un sentido similar, Vallejo Girvés 2000-2001: 23-25.
Se trataría de una construcción financiada por él mismo, ${ }^{96}$ pero lo que llama especialmente la atención es la reclamación del protagonismo episcopal en el proceso fundacional, muy similar al que Pimenio reivindica en las consagraciones hechas bajo su iniciativa. ${ }^{97}$ De hecho, podríamos plantear que la plasmación del nombre del obispo en este tipo de epígrafes obedecía en muchas ocasiones a esta situación de competencia entre prelados vecinos, que habrían buscado de esta forma dar propaganda a sus respectivas acciones fundacionales en detrimento de sus homólogos. Sabemos de otras inscripciones fundacionales que, aunque fueron hechas por o en nombre de un obispo concreto, no sentían la necesidad de dejar constancia de ello. ${ }^{98}$ Esto se podía deber a que el auditorio receptor de tales textos daba por supuesta la responsabilidad de la consagración del lugar a un obispo determinado y, por consiguiente, que este último no veía amenazados sus intereses sobre una región concreta, al menos no hasta el punto de necesitar remarcar su actividad frente a la de sus homólogos vecinos. Disponemos de algunas inscripciones relativas a la consagración de basílicas en zonas cercanas a la sede episcopal o en la propia ciudad en las que aparece el nombre del obispo de turno, pero parece ser que en estos casos tales añadidos constituían únicamente una forma de datación..$^{99}$ Caso contrario sería el de los epígrafes relativos a las acciones de Pimenio en Salpensa, la de Oroncio en Ibahernando o la de Paulo en Nativola, en las que se pone claramente de manifiesto que la consagración de las respectivas basílicas se llevó a cabo por la iniciativa episcopal de estos individuos con la previsible intencionalidad de no dar pie a confusión con otros obispos del entorno. ${ }^{100}$

Finalmente, los monasterios también habrían desempeñado un cierto papel a la hora de proyectar el poder del obispo sobre el territorio diocesano. A fin de cuentas, estos constituían también centros de poder y como tales se tienen que tomar en consideración. ${ }^{101}$ Advertimos, pues, una preocupación episcopal por controlar estos lugares desde su propia construcción, para la cual se requería el previo consentimiento del obispo. ${ }^{102}$ En algunos casos percibimos incluso la propia iniciativa episcopal detrás de la fundación de determinados monasterios. ${ }^{103}$ Los esfuerzos de los prelados también se dirigieron a la imposición sobre las comunidades monásticas de una Regla aprobada previamente por la autoridad episcopal, así como a la absorción bajo su jurisdicción y control directos del funcionamiento interno de estos centros, incluido el nombramiento formal del abad. ${ }^{104}$

\footnotetext{
96 ICERV, 313; CIL A, II-1, 606. Cf. Duval 1993: 180.

97 Castillo Maldonado 2003: 455.

98 Duval 1993: 184-186.

99 Ibídem: 189. No sabemos las circunstancias concretas para la consagración de tales basílicas, pero cabe la posibilidad de que se tratasen de fundaciones privadas sancionadas por el propio Pimenio; Castillo

100 Duval 1993: 189-190.

101 Cf. Le Jan 2001: 243-269.

102 Conc. Agath. (a. 506), c. 27, 294-304; Conc. Tarrac. (a. 516), c.
} Maldonado 2003: 453. $11,124-125$, donde se establece que los monjes sigan lo prescrito en los cánones de los concilios galos; Conc. Barcinon. (a. 540), c. 10. Cf. Díaz 1987: 16

103 Díaz 2017: 477-480, donde se aporta una casuística bastante completa; Velázquez 2007: 265-266.

104 Conc. Ilerd. (a. 546), c. 3, 52-63. Cf. Díaz 2017: 463-490. 
Sin embargo, dada la ausencia de una casuística significativa para estudiar el monacato bajo dependencia episcopal, preferimos relativizar su importancia en la articulación territorial de las diócesis, en favor de las iglesias rurales.

LAS DISPUTAS EPISCOPALES EN TORNO AL TERRITORIO: ¿UNA CUESTIÓN DE LÍMITES?

En esta concepción más social de la diócesis que venimos defendiendo a lo largo del presente trabajo nos surge un problema, como son las disputas episcopales por cuestiones territoriales. Hemos tenido ocasión de analizar el caso de Pimenio y la competencia apuntada entre los titulares de las sedes de Assidona y Sevilla por una misma área de influencia, pero posiblemente este episodio no tuvo mayores consecuencias. En otras ocasiones, sin embargo, las tensiones podían aumentar en intensidad, dando pie a disputas abiertas entre obispos. Son numerosos los testimonios que recogen quejas por supuestas intromisiones de determinados prelados en el ámbito de jurisdicción de alguno de sus homólogos vecinos. ${ }^{105} \mathrm{~A}$ lo largo del siguiente apartado profundizaremos en los casos más destacados, tratando de presentar una perspectiva alternativa a la clásica lucha por límites territoriales defendida generalmente por la historiografía. De este modo, consideramos que la centralidad en tales litigios la tenía sobre todo el control social de sus habitantes, ${ }^{106}$ y por extensión el interés por mantener el dominio y la propiedad sobre un territorio difuso. Obviamente estas disputas habrían surgido en aquellas zonas donde se solapaban las redes de influencia de una y otra diócesis. Podríamos decir incluso que, de forma indirecta, apuntan precisamente a la ausencia de unas circunscripciones claramente definidas. En caso contrario no se entenderían las reivindicaciones de derechos sobre los mismos lugares por cada una de las partes. ${ }^{107}$

El primero de los casos a reseñar donde quedan claramente de manifiesto las dinámicas señaladas es el concerniente a la competencia entre el obispo Montano de Toledo y el titular de Astorga por el control de un sector de la diócesis de Palencia, conocida gracias a las cartas que conservamos del primero anexas a las actas conciliares del II Concilio de Toledo. ${ }^{108} \mathrm{El}$ origen del problema radica en la arrogación por parte de Montano del derecho a intervenir en los asuntos de la diócesis palentina. Para ello se habría amparado en la supuesta antigüedad de sus privilegios metropolitanos sobre la región, a pesar de que sabemos que su condición como cabeza de una provincia eclesiástica fue adquirida

105 Por ejemplo, Braul., Epist. XVII. Ed. L. Riesco Terrero, 1975. Epistolario de San Braulio. Introducción, edición crítica y traducción: 98. Sevilla: Publicaciones de la Universidad de Sevilla.

106 Haciéndonos eco de nuevo de las palabras de Lauwers (2008: 31), «ce n'est pas en faisant établir des lignes de partage et des bornes que se trouvaient apaisés les conflits; la formation de liens de nature personnelle entre les membres de la hiérarchies ecclésiale, les clercs et les fidèles paraît alors avoir joué un rôle majeur dans l'organisation des pouvoirs".

107 En estos términos se manifiesta Le Gall-Tanguy 2017: 39.

108 La primera de estas cartas habría estado dirigida al clero palentino, mientras que la segunda habría tenido como destinatario a un personaje de nombre Toribio. Conc. II Tol. (a. 531), 132-234; 235-286. recientemente. ${ }^{109}$ En consecuencia, lo más probable es que el propio Montano hubiese exagerado en lo referente a sus hipotéticos derechos para imbuirse de una mayor legitimidad e imponerse sobre el propio obispo de Astorga y los clérigos de la diócesis palentina a los que se dirigía. ${ }^{110} \mathrm{De}$ hecho, sabemos que en realidad la diócesis palentina nunca estuvo integrada en la Carthaginensis, de la cual Montano se había escindido para crear la nueva provincia eclesiástica carpetana, sino en la Gallaecia. ${ }^{111}$ Estaríamos hablando, por lo tanto, de una región cuya inclusión práctica en la nueva provincia de Carpetania estaba lejos de ser una realidad. De esta manera, la integración de Palencia y el norte de la Submeseta Norte en la nueva provincia eclesiástica, más que reflejar una instauración de facto de la nueva autoridad metropolitana, estaría mostrando el carácter potencial de la misma.

Montano habría aprovechado una situación de vacancia en la sede palentina para extender sus redes de influencia personales sobre una diócesis que había escapado hasta entonces de su autoridad metropolitana. Para ello exigió a los presbíteros repartidos por la diócesis palentina que viajasen a Toledo para recibir el crisma que, por la normativa canónica, se les prohibía consagrar por ellos mismos, a pesar de que lo habían estado haciendo hasta entonces. ${ }^{112}$ No se trataba de una cuestión baladí, puesto que Montano lograba de esta manera mantener a estos individuos bajo control y forzarles a rendir cuentas, así como, en el caso preceptivo, deponerlos y sustituirlos por otros presbíteros más proclives a aceptar su voluntad. Actuando de esta manera, junto a la acción proselitista realizada en la zona por su agente Toribio, ${ }^{113}$ Montano procuró asegurarse la adhesión personal del clero palentino y, por tanto, extender su influencia fáctica sobre la región. Tendríamos así una prueba más de la importancia de las relaciones personales a la hora de implantar el poder episcopal sobre el territorio y sus habitantes. El problema radicaba en el hecho de que al mismo tiempo que Montano actuaba sobre la región, el obispo de Astorga hacía lo propio consagrando iglesias en territorio palentino, ${ }^{114}$ con la consiguiente toma bajo su dependencia de las mismas. Al fin y al cabo, la fundación y consagración de iglesias se trataba del mecanismo principal a disposición de un obispo para tomar bajo su control el ámbito rural y extender la jurisdicción de su diócesis. Se advierte así una competencia abierta entre el metropolitano toledano y el obispo asturicense en torno a una misma área de influencia. Para hacer frente a esta situación, Montano reclamará su jurisdicción sobre el territorio palentino de acuerdo a criterios territoriales y jurídicos, la circunscripción de la pro-

109 Cf. Codoñer 1972: 61-64; Mansilla Reoyo 1991: 531.

110 Martin 1998: 406

111 Escalona Monge 2006: 177-178.

112 Conc. II Tol. (a. 531), 197-201. Tal exigencia no fue un fenómeno exclusivo de la realidad ibérica, sino que disponemos de numerosos testimonios para la Galia merovingia y carolingia que muestran la misma obligatoriedad de los presbíteros hacia la autoridad episcopal; Mazel 2016: 112-114.

113 Conc. II Tol. (a. 531), 242-243. Sobre esta figura, Martin 1998: 416-417; Isla 2000-2001: 44-45; Díaz 2006: 52.

114 Conc. II Tol. (a. 531), 202-203, 206-210. Suponemos que se trataría del obispo de Astorga, al ser su diócesis la más cercana y, por tanto, lindante con la palentina. Sobre el origen del obispo en cuestión, Martin 2007: 215-216. 
vincia eclesiástica que él encabezaba — con independencia de la legitimidad real de su condición metropolitana-, en un mundo en el que la autoridad se ejercía fundamentalmente a partir del establecimiento de un entramado más o menos denso de relaciones personales de poder. ${ }^{115} \mathrm{El}$ propio Montano era consciente de ello, de ahí que su reclamación viniese acompañada con una acción paralela de extensión de los vínculos sociales y de dominación con el clero palentino, a sabiendas de que esta era la única manera de absorber bajo su dependencia real la región en liza. No sabemos cómo se resolvió finalmente la cuestión. Debemos suponer que Montano acabó teniendo éxito en su empresa, logrando la resignación del obispo asturicense, quien por su parte habría evitado la confrontación abierta con el metropolitano de Toledo; actitud en la que creemos que influyó el apoyo granjeado por la monarquía visigoda a su rival. ${ }^{116}$

Posteriormente, para el territorio bético, las actas de II Concilio de Sevilla del 619 dejan constancia de otras disputas episcopales por cuestiones territoriales. En el primero de los cánones se recogen las quejas del obispo Teodulfo de Málaga, cuya diócesis había sido recientemente incorporada al Regnum Gothorum, contra los obispos vecinos de Astigi (Écija), Iliberris (Granada) y Egabrum (Cabra). A estos los acusa de haberle privado de la jurisdicción sobre partes que originalmente habían formado parte de su diócesis. Según establece el propio canon, estas se perdieron a raíz de los ataques visigodos sobre la región - posiblemente en tiempos de Leovigildo- ${ }^{117}$ y, como consecuencia de estos, de la incorporación parcial del espacio diocesano malacitano al reino visigodo, lo que habría provocado su ulterior reparto entre los citados obispados. ${ }^{118}$ En lo que respecta a la cuestión a tratar, ciertamente dicha queja presenta una reclamación del territorio perdido, pero en ningún momento esta se presenta en términos de límites, ${ }^{119}$ sino que únicamente alude a «ex parte» de la diócesis. De este modo, es posible que, atendiendo a lo anteriormente expuesto, la disputa se hubiese generado no tanto en torno a una supuesta circunscripción diocesana, como por la jurisdicción sobre determinadas iglesias y los feligreses adscritos a ellas.

El canon conciliar fallará en favor de Teodulfo. En concreto, los obispos reunidos en concilio concederán al titular malacitano la jurisdicción sobre las partes reclamadas basándose, por un lado, en el supuesto derecho antiguo disfrutado sobre las mismas y, por otro, en la normativa civil, concretamente en la ley relativa al postliminium, heredada del Codex Theodosianus y en vigencia a través del Breviario de Alarico. ${ }^{120}$ Llama la atención precisamente que

115 Además, debemos de tener en cuenta que la nueva provincia eclesiástica no se correspondía territorialmente con ninguna circunscripción tradicional, ni eclesiástica ni civil; Escalona Monge 2006: 177-178.

116 Díaz 2008: 138.

117 Vallejo Girvés 2012: 359.

118 Conc. II Hisp. (a. 619), c. 1.

119 Todo ello a pesar de las tentativas hipotéticas de reconstrucción emprendidas por algunos especialistas; Salvador Ventura 2012: 246.

120 Conc. II Hisp. (a. 619), c. 1: «Pro qua re placuit ut omnis parrochia quae ab antiqua ditione ante militarem hostilitatem retinuisse ecclesiam suam conprobaret eius privilegio restitueretur. Sicut enim per legem munidalem his quos barbarica feritas captiva necessitate transvexit, postliminio revertentibus redditur antiquea possessio, non aliter [et] ecclesia receptura parrochiam quam ante retinuit cum suis, sive $a b$ aliis ecclesiis possideantur sive in cui[us]libet possessione transfusa se esgrima la legislación civil como método resolutivo de un conflicto estrictamente eclesiástico, frente a otro tipo de argumentos. ${ }^{121}$ Da la impresión de que se actuó de esta manera con el propósito concreto de eludir la aplicación de la norma canónica de la tricennalia, ${ }^{122}$ la cual establecía que toda iglesia y propiedad que hubiese estado más de 30 años bajo posesión de un obispo sin recibir reclamación alguna debía quedar definitivamente adscrita a su jurisdicción. ${ }^{123}$ Por otra parte, resulta también curioso el hecho que este sea el único caso en el que presenciamos este tipo de demandas por parte de un obispo que hasta entonces había formado parte del Imperio, más a sabiendas de que otros tantos prelados se vieron en la misma situación, solo que en estos casos no tenemos constancia de queja o disputa alguna dirigida a recuperar lo otrora perdido. ${ }^{124}$ Por nuestra parte, consideramos que una posible explicación a la actitud adoptada en el II Concilio de Sevilla se halla en el propio contexto en el que este tuvo lugar.

Aunque la toma de Málaga y su territorio se llevó previsiblemente a cabo por la vía violenta, lo cierto es que los visigodos y sus obispos requerían el apoyo y la colaboración del propio prelado malacitano para imponer con mayor facilidad una dominación real sobre la región, más si atendemos al papel de liderazgo comunitario ejercido por la figura episcopal en estos momentos y a su capacidad para mover voluntades entre sus feligreses. ${ }^{125}$ Obviamente el favor episcopal no se podía conseguir con la vía impositiva, sino recurriendo al pacto. De este modo, cabe la posibilidad de que la «devolución» de los territorios en liza hubiese formado parte de las negociaciones entabladas para atraerse a Teodulfo a la causa visigoda. Es posible incluso que los supuestos derechos antiguos reclamados por la sede malacitana sobre los territorios en cuestión no constituyan más que la justificación asumida por el concilio para satisfacer las ambiciones de Teodulfo de ampliar su jurisdicción y su poder, más teniendo en cuenta el tiempo pasado desde la pretendida pérdida parcial de su espacio diocesano - en caso de aceptar que esta se produjo en tiempos de Leovigildo-. Teodulfo habría recurrido así a la vía rápida, aprovechándose de la situación ventajosa en la que se encontraba, en lugar de extender por sí mismo las redes de influencia sobre dicho territorio.

Las mismas actas del II Concilio de Sevilla recogen en su canon 2 otra disputa por cuestiones territoriales, cuya resolución se lleva a cabo de distinta manera. En esta ocasión los obispos Fulgencio de Écija y Honorio de Córdoba litigan por una única iglesia. En concreto, discuten por la sujeción de la misma a su respectiva autoridad episcopal de acuerdo a los 
límites de los distritos Celticense (Peñaflor), teóricamente bajo la jurisdicción de la diócesis de Astigi, y Reginense (Reina), adscrito a la sede cordobesa. Para la resolución de dicho conflicto, los padres conciliares determinan el envío de inspectores que investiguen y averigüen la localización de señales o mojones fronterizos antiguos («veteribus signis limes») que esclarezcan si la referida iglesia se encuentra dentro de los límites territoriales de una u otra localidad. ${ }^{126}$

Este es el único caso en el que se presenta una disputa aludiendo a términos territoriales. Sin embargo, esta no surge en torno a la supuesta circunscripción en sí misma, sino por la ambición de controlar una iglesia determinada. ${ }^{127}$ La mención a los propios límites se esgrime para justificar la usurpación por uno u otro lado de la jurisdicción sobre la susodicha basílica. Sin embargo, no podemos ignorar aquí la referida alusión a los mismos y a su papel desempeñado en este asunto. ¿Estaríamos por tanto ante la prueba de la existencia de unas circunscripciones claramente definidas y en vigencia? En realidad, consideramos que el propio canon revela todo lo contrario. La indefinición territorial era tal en estos momentos, tanto en lo referido a las circunscripciones administrativas como diocesanas, que se tenía que recurrir a antiguos marcadores territoriales, de los cuales no conocían su localización o, incluso, si estos existían ciertamente. En caso contrario, no se habría tenido que recurrir a los referidos inspectores. A esto se le une, como apuntamos más arriba, el cuestionamiento que se ha hecho en los últimos años a la delimitación lineal sistemática e inmutable de los límites territoriales de las ciudades romanas. De esta forma, es posible que los mojones se hubiesen situado únicamente en aquellas zonas más pobladas o en disputa con las ciudades vecinas y que estos se hubiesen ido desplazando en función de cada coyuntura político-administrativa o social. ${ }^{128}$ Por consiguiente, debemos plantear la posibilidad de que para el caso a tratar ni siquiera se hubiese dispuesto de mojones que marcasen los antiguos límites urbanos. Atendiendo a todo esto, posiblemente no estemos más que ante una solución de compromiso del concilio, que prefirió eludir la resolución definitiva del asunto en favor de uno u otro lado. De todas formas, los propios padres sinodales dejan abierta una vía alternativa para resolver el litigio planteando la aplicación de la norma conciliar de la prescripción tricenal. Al fin y al cabo, se trata de una medida concebida para hacer frente a este tipo de situaciones, es decir, cuando un obispo determinado ha ejercido la jurisdicción sobre una o varias iglesias, y por extensión sobre sus respectivos clérigos y feligreses, que previamente habían estado bajo dependencia de otro prelado. Por lo tanto, se trata de una norma que se aplica, no por criterios territoriales, sino cuando dicho obispo ha extendido sus redes personales de poder sobre

126 Conc. II Hisp. (a. 619), c. 2.

127 Conc. II Hisp. (a. 619), c. 2 : «[...] episcopos discussio agitata est propter parrochiam baselicae, quam horum alter Celtisensen alter Reginensem adseruit; et quia inter utrasque partes hactenus limitis vindicata est [...]».

128 Sablayrolles 2002: 308, quien llega a afirmar que «la définition des limites était donc variable: elles furent plus ou moins précises suivant les époques, en fonction des données que nous venons d'évoquer, et susceptibles de varier avec les temps en fonction des mêmes impératifs», empleando así el caso de Tolosa como ejemplo; Lopes 2003: 55-67, esp. 61-65; Mazel 2016: 180. Véase también Chouquer 2010. tales lugares, revelando una vez más el carácter más social que territorial de la jurisdicción diocesana.

La última disputa conocida es la recogida en las actas conciliares del Concilio de Mérida del año 666, un concilio de carácter provincial, donde se reunieron previsiblemente todos los obispos de la provincia eclesiástica lusitana. Su canon octavo se hace eco de una disputa entre los obispos Sclua y Justo, titulares de las sedes de Egitania y Salmantica, respectivamente. ${ }^{129}$ Parece ser que Sclua, al hilo de la reincorporación de su obispado a esta provincia eclesiástica, aprovechó la situación para reclamar aquellos territorios que supuestamente habían estado bajo la jurisdicción de la sede egitana antes de que estos hubieran sido integrados en la diócesis salmantina a raíz de su conquista por los visigodos. El concilio dispone resolver el asunto en favor de Sclua de acuerdo a la aplicación de la norma tricenal, eso sí, contando los treinta años a partir de la reincorporación de la sede egitana a la provincia eclesiástica de Lusitania. En este caso también observamos que se mandan «inspectores» para supervisar que el traspaso se hiciera correctamente, buscando "evidentiae signa» que ayudasen a identificar aquellas partes a traspasar a la sede egitana. Ahora bien, no se alude explícitamente a la búsqueda de unos marcadores territoriales. Es decir, la cuestión se deja abierta, puesto que posiblemente el propio concilio no tenía confianza en aquellos elementos sobre los que se apoyaba el obispo Sclua para sustentar su reclamación.

Este concilio provincial se ha planteado siempre como una disputa de términos de límites entre las diócesis de Salamanca y la de Egitania. En concreto se ha considerado que los obispos lusitanos buscaron una restauración de las demarcaciones diocesanas previas a la conquista sueva del territorio. ${ }^{130}$ Sin embargo, en el canon la disputa no se presenta en ningún momento en tales términos, sino que únicamente se alude a una porción de la diócesis, sin mayor precisión. A tenor de las disputas apuntadas previamente, podríamos plantear que la disputa deriva de un conflicto de intereses sobre determinadas iglesias rurales y, por extensión, sobre el territorio que estas controlaban. La propia alusión a la norma canónica de la prescripción tricenal, que concierne a la posesión de ecclesiae, apunta hacia esta dirección.

Sin embargo, en todo este esquema hay un elemento que resulta difícil de encajar. Como hemos anotado, la disputa se produjo entre las diócesis de Egitania y la de Salmantica, vecinas una de la otra. Sin embargo, sus respectivas sedes se encontraban bastante alejadas, lo que contrasta enormemente con la proximidad de la sede de Coria respecto a la egitana. A esto se le une, además, la relativamente reciente fundación de la diócesis cauriense, que obviamente, dada su cercanía con la egitana, habría tomado parte de las bases territoriales originales de esta última para conformar su propio espacio diocesano. Ante tales evidencias, sorprende que la reclamación territorial del obispo Sclua se haga contra Salmantica y no contra su vecino más cercano. De esta forma, es posible que las reivindicaciones del concilio emeritense hubiesen respondido a una disputa coyuntural, enmascarada con argumentaciones de tipo histórico. A fin de cuentas, se trataba de un territorio que, en caso de haber

129 Conc. Emer. (a. 666), c. 8.
130 Cf. Díaz 1992: 311-321, 1995: 51-72, esp. 65. 
formado parte de diócesis de Egitania, llevaba casi más de un siglo fuera de su jurisdicción. Sin embargo, sí debemos reconocer un choque de percepciones del territorio diocesano por parte de los obispos en cuestión. Mientras en el caso de la sede de Salmantica, su obispo se limita únicamente a seguir los patrones normales de extensión de su autoridad, es decir, tomando bajo su control una iglesia rural y su clero a través del establecimiento de relaciones de tipo personal; en el otro caso observamos que Sclua prefiere recurrir a argumentos jurídicos para apoderarse del territorio en disputa. Eso sí, el recurso a los mismos debemos entenderlo como una prueba de la propia incapacidad del propio prelado egitano para establecer vínculos personales con las comunidades cristianas implicadas, lo que le habría obligado a recurrir a estrategias alternativas.

Para resolver esta cuestión, se ha planteado que la propia sede salmantina recuperó al final parte del territorio supuestamente perdido, y que hasta esos momentos había estado bajo dominio de la sede metropolitana de Braga. ${ }^{131}$ Este hecho sirve como justificación para que el concilio falle a favor de Sclua, transmitiendo así la idea de que en realidad ninguna de las diócesis se vio perjudicada al haber logrado ambas ampliar su ámbito de influencia. Sin embargo, lo cierto es que los padres conciliares resuelven el asunto favoreciendo ante todo la causa de Egitania. Este hecho es bastante llamativo, dada la reciente reincorporación de esta sede episcopal a la provincia eclesiástica lusitana. Es posible que, en el contexto de las negociaciones para su inclusión en la misma, el obispo Sclua, a cambio de reconocer la autoridad metropolitana de Proficio de Mérida, pusiese sobre la mesa su conflicto con la sede salmantina, forzando así al metropolitano a unirse a su causa. ${ }^{132}$ Sería así como podríamos entender la propia normativa canónica y, en lugar de ser estrictos con la aplicación de la tan citada prescripción de los treinta años, el hecho de que los obispos decidieran poner el contador en marcha a partir de la reciente reincorporación de Egitania en la provincia lusitana.

Como balance, observamos que los conflictos episcopales por cuestiones territoriales o, en general, de poder fueron predominantes, por no decir los únicos de los que tenemos constancia, relegando, incluso ignorando, las cuestiones de tipo teológico o dogmático. ${ }^{133}$ Ciertamente, las disputas de este tipo habrían sido más numerosas, pero de forma mayoritaria nos han llegado aquellas que terminaron por dirimirse en concilio, ${ }^{134}$ concretamente las de más difícil resolución. De esta manera, el concilio o, en otras palabras, la toma de decisiones de forma consensuada y con san-

131 Díaz 1992: 320, 1995: 55.

132 Así se puede entender la curiosa suscripción del propio Sclua, siendo el único que remarca el carácter sufragáneo de su sede frente a Mérida. Conc. Emer. (a. 666), Subscriptiones: «Ego Sclua Igiditanae civitatis [ecclesiae] episcopus pertinens ad metropolim Emeritensem haec instituta cum archiepiscopo meo Proficio a nobis definita suscripsi».

133 Castillo Maldonado 2013: 300.

134 Por ejemplo, las actas del XI Concilio de Toledo hacen referencia a la discordia entre obispos. Conc. XI Tol. (a. 675), c. 4, 422-455. Aunque el canon conciliar no especifica los motivos de los conflictos en cuestión, debemos suponer que buena parte de los mismos derivaba de cuestiones territoriales. Asimismo, no negamos, tal y como ha planteado R. Lorenzo (2016: 280), que hubiera habido una disputa entre las sedes de Ilici y Eio poco después de la integración de la primera al Regnum Gothorum. ción de la divinidad, habría constituido el recurso judicial empleado para resolver un litigio cuando las distintas partes no llegaban a acuerdo. De hecho, buena parte de los concilios convocados pudieron obedecer a la necesidad de dirimir disputas eclesiásticas de distinto tipo. ${ }^{135}$ La mayoría, sin embargo, habría sido resuelta entre las propias partes por la vía del pacto, ${ }^{136}$ siendo así el sínodo el último recurso de apelación. En otros casos, los menos, ni siquiera se habría llegado a conflictos entre las partes, ante la permisividad mostrada por algunos obispos despreocupados de la pérdida de iglesias que hasta entonces habían estado bajo su jurisdicción. ${ }^{137}$ Las tensiones habrían surgido únicamente cuando dos o más obispos competían por un mismo espacio de influencia; todo ello, no olvidemos, enmarcado en un escenario en el que el poder episcopal se establecía a partir de relaciones personales, ya fuera con sus feligreses o con sus propios subordinados en el clero.

En última instancia, estas disputas revelan la incapacidad de obispos determinados por mantener bajo su control a sus iglesias y su clero, y por otra parte el oportunismo de sus homólogos vecinos que aprovechan la situación para extender sus redes personales de influencia sobre los mismos. Al mismo tiempo estas estarían confirmando el carácter cambiante de las diócesis hispanovisigodas, sumergidas en un permanente proceso de construcción y fluctuación territorial. ${ }^{138}$ También es cierto que el propio territorio diocesano y, por extensión, parroquial habría tomado conciencia de sus límites, llevando en consecuencia a una mayor delimitación, a partir del choque con los otros polos en expansión, ${ }^{139}$ aunque consideramos que para estos momentos la situación se encontraba en estado bastante germinal. Tales dinámicas se acabarían interrumpiendo con la invasión musulmana, sin poder llegar a plantear una delimitación estricta de las realidades territoriales diocesanas para el período visigodo.

\section{CONCLUSIONES}

A tenor de todo lo expuesto, podemos concluir afirmando que la concepción de diócesis episcopal imperante en la historiografía relativa al período visigodo puede cuestionarse y abrirse a nuevas perspectivas. Sin negar el carácter territorial de las realidades diocesanas, planteamos que el aspecto primordial que las definía era el elemento social y

135 Orlandis 1976: 81-88; Stocking 2000: 17, 38. Remarcando esta función de tribunales en la resolución de disputas para la Galia merovingia, Moore 2011: 83.

136 El canon 8 del Concilio de Mérida del 666 recoge la existencia de estos pactos entre partes: Conc. Emer. (a. 666), c. 8: «Pacta vero, quae iuxte canonicam regulam inter episcopos per pacificam deliberationem iustissime fuerint facta, in omnibus placet ese servanda».

137 A esta dirección apunta la petición de los obispos reunidos en el Concilio de Mérida del 666 para que ninguno de sus homólogos permita que se le arrebate parte alguna de sus respectivos espacios diocesanos. Conc. Emer. (a. 666), c. 8: "Omnibus vero episcopis id instituitur esse servandum, ut parrochia $[\mathrm{m}]$ sua $[\mathrm{m}]$ bene custodiant nec a quolibet fratre ea [m] usurpari permittant». Ahora bien, nunca debemos perder de vista la primacía del elemento social en el control del propio espacio. Es decir, más que por el territorio en sí mismo, los obispos habrían rivalizado por imponer su dominio sobre una misma comunidad de fieles. Lauwers 2008: 27.

138 Defendiendo la misma idea, aunque en un sentido de «delimitación» estricta, Lorenzo de San Román 2016: 276.

139 Cf. Zadora-Rio 2005: 105-120, 2016: 359-360. 
no tanto la existencia de unas circunscripciones claramente precisas. De este modo, la integridad territorial de las diócesis habría obedecido ante todo a la capacidad del obispo de turno por asegurarse el control del clero y los feligreses repartidos por el ámbito rural. En este punto, habría sido fundamental apuntalar el control directo de los distintos centros de culto rurales, a partir de los cuales el obispo extendía y reforzaba los lazos personales con la comunidad cristiana.

Se trataba de una tarea para nada exenta de dificultades. Concretamente, se habría tenido que hacer frente, por un lado, a las iniciativas privadas de las élites, las cuales lucharon por mantener celosamente la propiedad y el control de sus fundaciones eclesiásticas. Por otro lado, los propios obispos rivalizaron muchas veces entre sí por extender sus redes personales sobre una misma área de influencia. Esta competencia derivó ocasionalmente en disputas abiertas, que tuvieron que resolverse, bien por la vía del pacto, bien por la mediación de un tercero o, en última instancia, recurriendo al concilio. ${ }^{140}$ Ahora bien, insistiendo en la percepción propuesta de los territorios diocesanos hispanovisigodos, tales disputas no se habrían generado nunca por una cuestión de límites, sino por el control de determinadas iglesias y, por extensión, sobre el colectivo cristiano a ellas adscritas.

\section{FUENTES PRIMARIAS}

Braulio Caesaraugustanus, Epistolae. Ed. L. Riesco Terrero, 1975. Epistolario de San Braulio. Introducción, edición crítica y traducción. Sevilla: Publicaciones de la Universidad de Sevilla.

Braulio Caesaraugustanus, Vita Sancti Aemiliani. Ed. J. Oroz, 1978. "Sancti Bravlionis Caesaravgvstani episcopi. Vita Sancti Aemiliani». Perficit 9/119-120: 165-227.

Codex Theodosianus. Ed. Th. Mommsen, 1895. Theodosiani Libri XVI cvm Constitvtionibus, I-2. Berlin: apud Weidmannos.

Concilia Galliae, a. 511 - a. 695. Ed. C. de Clercq, 1963. CC, Series Latina, 148A. Turnhout: Brepols.

Concilios visigóticos e hispano-romanos. Ed. J. Vives, 1963. BarcelonaMadrid: CSIC.

Corpus de Inscripciones Latinas de Andalucía. Vol. II. Sevilla. Tom. II. La Campiña. Ed. J. González Fernández, 1996. Sevilla: Junta de Andalucía.

Corpus de Inscripciones Latinas de Andalucía. Vol. IV. Granada. Ed. M. Pastor, 2002. Sevilla: Junta de Andalucía.

Gelasius, Epistolarum fragmenta. Ed. A. Thiel, 1868. Epistolae romanorum pontificum genuinae, I. Brunsberg: E. Peter.

Inscripciones cristianas de la España romana y visigoda. Ed. J. Vives, 1942. Barcelona: CSIC.

La colección canónica hispana, IV-VI. Ed. G. Martínez Díez y F. Rodríguez, 1984-2002. Madrid: CSIC.

Les conciles œecuméniques. Les Décrets. Tome II-1. Nicée I à Latran V. Ed. G. Alberigo J. A. Dossetti, P.-P. Joannou, C. Leonardi, P. Prodi y H. Jedin, 1994. Paris: Les Éditions du Cerf

Valerius Bergidensis, Replicatio Sermonvm a prima conversione. Ed. M. C. Díaz y Díaz, 2006. Valerio del Bierzo. Su persona. Su obra. León: Centros de Estudios e Investigación «San Isidoro»-Caja España de Inversiones-Archivo Histórico Diocesano.

Vitas Sanctorum Patrum Emeretensium. Ed. A. Maya Sánchez, 1992. CC, Series Latina, 116. Turnhout: Brepols.

140 Tendríamos un paralelo en la Galia merovingia, donde se regula en concilio la vía a seguir ante disputas por cuestiones territoriales. Conc. Aurelian. (a. 541), c. 12. Ed. C. de Clercq, 1963. Concilia Galliae, $a$. 511-a. 695: 135.

\section{BiBLIOgRAFÍA}

Abasolo, J. A. 1999. «La ciudad romana en la Meseta Norte durante la Antigüedad tardía», en L. A. García Moreno y S. Rascón Marqués (eds.), Complutum y las ciudades hispanas en la Antigüedad tardía: 87-95. Alcalá de Henares: Universidad de Alcalá.

Althoff, G. 2004. Family, Friends and Followers. Political and Social Bounds in Early Medieval Europe. Cambridge: Cambridge University Press.

Arce Sainz, F. y Moreno Martín, F. J. 2012. «La construcción e iglesias como herramienta para el conocimiento del territorio tardoantiguo y altomedieval en la Meseta Norte», en L. Caballero Zoreda, P. Mateos Cruz y T. Cordero Ruiz (eds.), Visigodos y omeyas. El territorio: 97-122. Mérida: CSIC-Junta de Extremadura-Consorcio de Merida.

Aupest-Conduché, D. 1978. "Frontières des diocèses et limites des cités gallo-romaines aux $\mathrm{V}^{\mathrm{e}}$ et $\mathrm{VI} \mathrm{I}^{\mathrm{e}}$ siècles. Un exemple : la Péninsule Armoricaine", en La guerre et la paix, frontières et violences au Moyen Âge : actes du 101e Congrès national des sociétés savantes, Lille, 1976: 383-391. Paris: Bibliothèque Nationale.

Barbero de Aguilera, A. 1989. "Las divisiones eclesiásticas y las relaciones entre la Iglesia y el Estado en la España de los siglos VI y VII», en Mà. J. Hidalgo de la Vega (ed.), La historia en el contexto de las ciencias humanas y sociales. Homenaje a Marcelo Vigil Pascual: 169-190. Salamanca: Ediciones Universidad de Salamanca.

Barbero, A. y Vigil, M. 1978. La formación del feudalismo en la Península Ibérica. Barcelona: Crítica.

Bidagor, R. 1933. La 'iglesia propia' en España. Estudio histórico canónico. Roma: Pontificiae Universitatis Gregorianae.

Boissellier, S. 2016. «La délimitation des territoires locaux. Propositions et acquis», en N. Baron, S. Boissellier, C. François y F. Sabaté (dirs.), Reconnaître et délimiter l'espace localement au MoyenÂge, Limites et frontières (vol. I): 9-16. Villeneuve-d'Ascq: Presses Universitaires du Septentrion.

Bowes, K. 2008. Private Worship, Public Values, and Religious Change in Late Antiquity. New York: Cambridge University Press.

Brighenti, A. M. 2010. «On Territorology. Towards a General Science of Territory». Theory, Culture \& Society 27 (1): 52-72. https://doi.org/10.1177/0263276409350357

Brogiolo, G. P. y Chavarría Arnau, A. 2008. «Chiese, territorio e dinamiche del popolamento nelle campagne tra tardoantico el altomedioevo". Hortus Artium Medievalium 14: 7-29. https://doi.org/10.1484/j.ham.2.305436

Brown, P. 2012. Through the Eye of a Needle: Wealth, the Fall of Rome, and the Making of Christianity in the West, 350-550 AD. PrincetonOxford: Princeton University Press.

Cantino Wataghin, G. 2013. "Le fondazioni ecclesiastiche nelle vicende delle aree rurali spunti di riflessione per l'Occidente tardo antico (IV-V secolo)». Antiquité Tardive 21: 189-204. https://doi.org/10.1484/j.at.5.101411

Canto de Gregorio, A. M. 1995. «Inscripción conmemorativa de tres iglesias», en Arte islámico en Granada. Propuesta para un Museo de la Alhambra. Catálogo de la Exposición: 343-346. Granada: Junta de Andalucía.

Carbonell i Manils, J. y Gimeno Pascual, H. 2010. «A vueltas con la placa de Nativola (CIL II5/5, 652). Nuevos elementos para la reflexión». Sylloge Epigraphica Barcinonensis 8: 73-96.

Castellanos, S. 2006. «Ofensivas aristocráticas y articulación política en el norte hispano post-romano», en U. Espinosa y S. Castellanos (eds.), Comunidades locales y dinámicas de poder en el norte de la Península Ibérica durante la Antigüedad Tardía: 141-163. Logroño: Universidad de La Rioja.

Castellanos, S. 2016. "El obispo como líder ciudadano», en S. Acerbi, M. Marcos y J. Torres (eds.), El obispo en la Antigüedad tardía. Homenaje a Ramón Teja: 101-115. Madrid: Editorial Trotta.

Castellanos, S. y Martín Viso, I. 2005. «The Local Articulation of Central Power in the North of the Iberian Peninsula (500-1000)». Early Medieval Europe 13 (1): 1-43. https://doi.org/10.1111/j.1468-0254.2005.00147.x

Castillo Maldonado, P. 2003. «El obispo Pimenio de Asido y su actividad en la dedicación de basílicas», en Actas del III Congreso de Historia 
de Andalucía, Historia Antigua: 443-458. Córdoba: Publicaciones Social y Cultural Cajasur.

Castillo Maldonado, P. 2005. «Pro amore dei: donantes y constructores en la provincia Baetica tardoantigua (testimonios literarios y epigráficos)». Antiquité Tardive 13: 335-350. https://doi.org/10.1484/j.at.2.301787

Castillo Maldonado, P. 2013. «El cristianismo y las iglesias del sur peninsular en la Antigüedad tardía: balance histórico». Habis 44: 281-303.

Cepas, A. 2006. "The Ending of the Roman City: the Case of Clunia in the Northern Plateau of Spain», en W. Davies, G. Halsall y A. Reynolds (eds.), People and Space in the Middle Ages, 300-1300: 187-207. Turnhout: Brepols.

Chavarría Arnau, A. 2010. "Churches and Aristocracies in SeventhCentury Spain: Some Thoughts on the Debate on Visigothic Churches». Early Medieval Europe 18 (2): 160-174. https://doi.org/10.1111/j.1468-0254.2010.00294.x

Chouquer, G. 2007. "Quels territoires les pouvoirs fabriquent-ils?», en Ph. Rodriguez (ed.), Pouvoir et Territoire I (Antiquité-Moyen Âge): 295-314. Saint-Étienne: Publications de l'Université de Saint-Étienne.

Chouquer, G. 2010. La Terre dans le monde romain. Anthropologie, droit, géographie. Paris: Éditions Errance.

Codoñer, C. 1972. El 'De viris illustribus' de Ildefonso de Toledo: estudio y edición crítica. Salamanca: Universidad de Salamanca.

Codou, Y. 2008. "Aux confins du diocèse. Limites, enclaves et saints diocésains en Provence au Moyen Âge», en F. Mazel (dir.), L'espace du diocèse. Genèse d'un territoire dans l'Occident médiéval: 195212. Rennes: Presses Universitaires de Rennes.

Cohen, M.; Fanny, M. e logna-Prat, D. 2014. «Introduction», en M. Cohen y M. Fanny (eds.), Space in the Medieval West: Places, Territories and Imagined Geographies: 1-20. Farnham: Ashgate.

Collins, R. 1980. "Mérida and Toledo: 550-585», en E. James (ed.), Visigothic Spain. New Approaches: 189-210. Oxford: Clarendon Press.

Delaplace, Ch. 2002. "Les origines des églises rurales ( $\mathrm{V}^{\mathrm{e}}-\mathrm{Vl} \mathrm{I}^{\mathrm{e}}$ siècles). À propos d'une formule de Grégoire de Tours». Histoire \& Sociétés rurales 18 (2): 11-40.

Dey, H. W. 2014. The Afterlife of the Roman City. Architecture and Ceremony in Late Antiquity and the Early Middle Ages. Cambridge: Cambridge University Press.

Díaz, P. C. 1986. «Iglesia propia y gran propiedad en la Autobiografía de Valerio del Bierzo", en Actas I Congreso Internacional Astorga Romana: 297-303. Astorga: Ayuntamiento de Astorga.

Díaz, P. C. 1987. Formas económicas y sociales en el monacato visigodo. Salamanca: Ediciones Universidad de Salamanca.

Díaz, P. C. 1992. "Salamanca tardoantigua y visigoda», en Actas I Congreso Historia de Salamanca: 311-321. Salamanca: Diputación Provincial de Salamanca-Universidad de Salamanca.

Diaz, P. C. 1993. «El alcance de la ocupación sueva de Gallaecia y el problema de la germanización», en Galicia: da Romanidade á Xermanización. Problemas históricos y culturais: 209-223. Santiago de Compostela: Museo do Pobo Galego.

Díaz, P. C. 1995. «Propiedad y poder: la Iglesia lusitana en el siglo VII», en Los últimos romanos en Lusitania: 51-72. Mérida: Museo Nacional de Arte Romano.

Díaz, P. C. 1998. «El Parrochiale Suevum: organización eclesiástica, poder político y poblamiento en la Gallaecia tardoantigua», en J. Alvar (ed.), Homenaje a José Máría Blázquez, Vol. VI, Antigüedad: religiones y sociedad: 35-48. Madrid: Ediciones Clásicas.

Díaz, P. C. 2000. "City and Territory in Hispania in Late Antiquity», en G. P. Brogiolo, N. Gauthier y N. Christie (eds.), Towns and their Territories between Late Antiquity and the Early Middle Ages: 3-35. Leiden: Brill.

Díaz, P. C. 2006. "La cristianización de Cantabria antes del Beato», en P. Á. Fernández Vega (ed.), Apocalipsis. El ciclo histórico del Beato de Liébana: 45-69. Santander: Consejería de Cultura, Turismo y Deporte-Museo de Prehistoria y Arqueología de Cantabria.

Díaz, P. C. 2008. «Sedes episcopales y organización administrativa en la cuenca del Duero: siglos IV-VII», en S. Castellanos e I. Martín Viso (eds.), De Roma a los bárbaros. Poder central y horizontes locales en la Cuenca del Duero: 123-144. León: Universidad de León.

Díaz, P. C. 2011. El reino suevo (411-585). Tres Cantos: Akal.

Díaz, P. C. 2017. «Las fundaciones monásticas en la península ibérica (siglos VI-VIII)", en Monachesimi d'Oriente e d'Occidente nell'alto medioevo: 463-490. Spoleto: CISAM.

Díaz, P. C. y Menéndez Bueyes, L. R. 2005. «The Cantabrian Basin in the Fourth and Fifth Centuries: From Imperial Province to Periphery», en K. Bowes y M. Kulikowski (eds.), Hispania in Late Antiquity. Current Perspectives: 265-297. Leiden: Brill.

Duval, Y. 1991. «'Nativola-les-trois-églises’ (évêché d’Acci, 594-607) d'après Vives, ICERV, no 303». Mélanges de l'École Française de Rome 103: 803-820. https://doi.org/10.3406/mefr.1991.1736

Duval, Y. 1993. "Projet d'enquête sur l'épigraphie martyriale en Espagne romaine, visigothique (et bizantine)». Antiquité Tardive 1: 173-206. https://doi.org/10.1484/j.at.2.301199

Escalona Monge, J. 2006. «Patrones de fragmentación territorial: el fin del mundo romano en la Meseta del Duero», en U. Espinosa y S. Castellanos (eds.), Comunidades locales y dinámicas de poder en el norte de la Península Ibérica durante la Antigüedad tardía: 165199. Logroño: Universidad de La Rioja.

Escalona Monge, J. 2011. "The Early Middle Ages: A Scale-Based Approach», en J. Escalona y A. Reynolds (eds.), Scale and Scale Change in the Early Middle Ages: Exploring Landscape, Local Society, and the World Beyond: 9-30. Turnhout: Brepols.

Espluga Corbalán, M. X.; Mayer Olivé, M. y Miró Vinaixa, M. 1984. «Epigrafía de Begastri». Antigüedad y Cristianismo 1: 45-87.

Fernández, D. 2016. «Property, Social Status, and Church Building in Visigothic Iberia». Journal of Late Antiquity 9 (2): 512-141. https:// doi.org/10.1353/jla.2016.0022

Fernández Alonso, J. 1955. La cura pastoral en la España romanivisigoda. Roma: Iglesia Nacional Española.

Fletcher, R. 1998. The Barbarian Conversion. From Paganism to Christianity. New York: Henry Holt and Company.

Fuentes Hinojo, P. 2008. «Patrocinio eclesiástico, rituales de poder e historia urbana en la Hispania tardoantigua (siglos IV al VI)». Studia Historica. Historia Antigua, 26: 315-344.

García Moreno, L. A. 1985. «Vándalos, visigodos y bizantinos en Granada (409-711)», en N. Marín Díaz (coord.), In memoriam. Agustín Díaz Toledo: 121-147. Granada: Secretariado de Publicaciones de la Universidad de Granada.

García Moreno, L. A. 1990. «Élites e Iglesia hispanas en la transición del Imperio romano al reino visigodo", en J. M. Candau, F. Gascó y A. Ramírez de Verger (eds.), La conversión de Roma: cristianismo y paganismo: 223-258. Madrid: Ediciones Clásicas.

García Moreno, L. A. 1999. "La ciudad en la Antigüedad tardía (siglos V a VII)», en L. A. García Moreno y S. Rascón Marqués, (eds.), Complutum y las ciudades hispanas en la Antigüedad tardía: 7-23. Alcalá de Henares: Universidad de Alcalá.

García Moreno, L. A. 2007. "Transformaciones de la Bética durante la tardoantigüedad». Mainake 29: 433-471.

Gauthier, N. 2000. «Le réseau de pouvoirs de l'évêque dans la Gaule du Haut Moyen Âge», en G. P. Brogiolo, N. Gauthier y N. Christie (eds.), Towns and Their Territories between Late Antiquity and the Early Middle Ages: 173-207. Leiden: Brill.

Geertz, C. 1994. "Centros, reyes y carisma: una reflexión sobre el simbolismo del poder», en C. Geertz, Conocimiento local. Ensayos sobre la interpretación de las culturas: 147-171. Barcelona: Paidós.

Gimeno Pascual, H. 2009. «El hábito epigráfico en el contexto arquitectónico hispánico del siglo VII», en L. Caballero Zoreda, P. Mateos Cruz y Mà. Á. Utrero Agudo (eds.), El siglo VII frente al siglo VII: Arquitectura: 31-44. Madrid: CSIC.

Gottmann, J. 1973. The Significance of Territory. Charlottesville: University Press of Virginia.

Guerreau, A. 1996. "Quelques caractères spécifiques de l'espace féodal européen", en N. Bulst, R. Descimon y A. Guerreau (eds.), L'État ou le Roi : les fondements de la modernité monarchique en France (XIVe-XVII siècles): 85-101. Paris: Éditions de la Maison des Sciences de l'Homme. 
Gurt, J. M.a ; Ripoll, G. y Godoy, C. 1993. «Topografía de la Antigüedad Tardía hispánica. Reflexiones para una propuesta de trabajo». Antiquité Tardive 2: 161-180. https://doi.org/10.1484/j.at.2.301161

Halsall, G. 2007. Barbarian Migrations and the Roman West: 376-568. Cambridge: Cambridge University Press

Harrison, D. 2001. "Invisible Boundaries and Places of Power: Notion of Liminality and Centrality in the Early Middle Ages», en W. Pohl, I. Wood y H. Reimitz (eds.), The Transformation of Frontiers from Late Antiquity to the Carolingians: 83-94. Leiden: Brill.

Isla, A. 2000-2001. «Desde el reino visigodo y la ortodoxia toledana: la correspondencia de Montano». Studia Historica. Historia Antigua 18-19: 41-52.

Jones, R. 1999. «Mann and Men in a Medieval State: The Geographies of Power in Medieval States». Transactions of the Institute of British Geographers 24: 65-78. https://doi.org/10.1111/j.0020-2754.1999.00065.x

Jussen, B. 2001. «Liturgy and Legitimation, or How the Gallo-Romans Ended the Roman Empire», en B. Jussen (ed.), Ordering Medieval Society. Perspectives on Intellectual and Practical Modes of Shaping Social Relations: 147-199. Philadephia: University of Pennsylvania Press.

Kulikowski, M. 2004. Late Roman Spain and Its Cities. BaltimoreLondon: The John Hopkins University Press.

Kulikowski, M. 2005. "Cities and Government in Late Antique Hispania», en M. Kulikowski (ed.), Hispania in Late Antiquity. Current Perspectives: 31-75. Leiden: Brill.

Larrañaga Elorza, K. 1989. «En torno al caso del obispo Silvano de Calagurris: consideraciones sobre el estado de la Iglesia del Alto y Medio Ebro a fines del Imperio». Veleia: Revista de Prehistoria, Historia Antigua, Arqueología y Filología Clásicas 6: 171-190.

Lauwers, M. 2005. "Paroisse, paroissiens et territoire. Remarques sur parochia dans les textes latins du Moyen Âge». Médiévales 49: 11-32. https://doi.org/10.4000/medievales.1260

Lauwers, M. 2008. «Territorium non facere diocesim. Conflits, limites et représentation territoriale du diocèse $\left(\mathrm{V}^{\mathrm{e}}-\mathrm{X}^{\mathrm{e}}\right.$ siècle)", en $\mathrm{F}$. Mazel (dir.), L'espace du diocèse. Genèse d'un territoire dans l'Occident médiéval ( $V^{e}$-XIII siècle): 23-68. Rennes: Presses Universitaires de Rennes.

Le Gall-Tanguy, R. 2017. «La formation des espaces diocésaines en León, Cornouaille et Trégor $\left.\left(\mathrm{V}^{\mathrm{e}}-\mathrm{XIII}\right)^{\mathrm{e}}\right)$, en N. Baron, S. Boissellier, F. Clément y F. Sabaté (dirs.), Ériger et borner diocèses et principautés au Moyen Âge, Limites et frontières (vol. II): 21-44. Villeneuve d'Ascq: Presses Universitaires du Septentrion.

Le Jan, R. 2001. "Convents, Violence, and Competition for Power in Seventh-Century Francia», en M. de Jong, F. Theuws y C. van Rhijn (eds.), Topographies of Power in the Early Middle Ages: 243-269. Leiden-Boston-Köln: Brill.

Le Jan, R. 2007. "Conclusion», en Ph. Depreux, F. Bougard y R. Le Jan (eds.), Les élites et leurs espaces. Mobilité, rayonnement, domination (du VIe au Xle siècle): 399-406. Turnhout: Brepols.

Le Roux, P. 2014. «La question des conventus dans la péninsule Ibérique d'époque romaine», en Espagnes romaines. L'empire dans ses provinces: 113-129. Rennes: Presses Universitaires de Rennes.

Lecanda, J. A. 1994. «El epígrafe consacratorio de Santa María de Mijangos (Burgos): Aportaciones para su estudio». Letras de Deusto 24 (65): 173-196.

Liebeschuetz, J. H. W. G. 2001. The Decline and Fall of the Roman City. Oxford-New York: Oxford University Press.

Lopes, M. C. 2003. "Réflexions sur le modèle de la cité antique: l'exemple de Pax Iulia (Beja, Portugal)». Études rurales 3-4 (167168): 55-67. https://doi.org/10.4000/etudesrurales.8019

Lorenzo de San Román, R. 2016. "Ecclesiae Ilicitanae, quie et Eiotanae, episcopus. Sobre la extensión y dualidad de la sede episcopal de Ilici en la Antigüedad tardía». Lvcentvm 35: 265-305. https://doi.org/10.14198/lvcentvm2016.35.15

Lunven, A. 2014. Du diocèse à la paroisse. Évêchés de Rennes, Dol et Alet/Saint-Malo (Ve-XIII siècle). Rennes: Presses Universitaires de Rennes.

Lunven, A. 2016. "Christianisation and Parish Formation in Early Medieval France: A Case Study of the Dioceses of Rennes, Dol and
St. Malo», en T. Ó. Carragáin y S. Turner (eds.), Making Christian Landscapes in Atlantic Europe: 325-344. Cork: Cork University Press.

Mansilla Reoyo, D. 1991. «Organización eclesiástica visigoda. La provincia Cartaginense», en III Concilio de Toledo, XIV Centenario, 5891989: 523-541. Toledo: Arzobispado de Toledo.

Martin, C. 1998. "Las cartas de Montano y la autonomía episcopal de la Hispania septentrional en el siglo VI». Hispania Antiqva 22: 403-423.

Martin, C. 2003. La géographie du pouvoir dans l'Espagne visigothique. Villeneuve d'Ascq: Presses Universitaires du Septentrion.

Martin, C. 2007. "Les évêques visigothiques dans leur espace : de l'autonomie à l'intégration", en F. Bougard, Ph. Depreux y R. Le Jan (eds.), Les élites et leur espace : mobilité, rayonnement, domination ( $V I^{e}-X I^{e}$ s.): 207-224. Turnhout: Brepols.

Martín Viso, I. 1999. «Organización episcopal y poder en la Antigüedad Tardía y el Medievo (siglos V-XI): Las sedes de Calahorra, Oca y Osma». Iberia 2: 151-190.

Martínez Díez, G. 1959. El patrimonio eclesiástico en la España visigoda. Estudio histórico-jurídico. Santander: Universidad Pontificia de Comillas.

Martínez Jiménez, J. y Tejerizo García, C. 2015. «Central Places in the Post-Roman Mediterranean: Regional Models for the Iberian Peninsula». Journal of Mediterranean Archaeology 28 (1): 81-103. https://doi.org/10.1558/jmea.v28i1.27502

Martínez Melón, J. I. 2008. «Aproximación al territorio de la diócesis de Astigi (Écija, Sevilla) en la antigüedad tardía». Pyrenae 39 (1): 115-128.

Mazel F., 2013. "Spatialisation et territorialisation des pouvoirs en Provence ( $X^{\mathrm{e}}-\mathrm{XII}$ e siècles) : quelques éléments de réflexion», en Territorium. Raum und Politik: Wahrnemung und Praxis im Frankreich und seine Nachforgereichen vom 9 bis zum 13. Jahrhundert, Tübingen: Eberhrd Karls Universität Tübingen. En línea:

<https://publikationen. uni-tuebingen. de/xmlui/handle/10900/47103> [Consultado el 17/10/2017].

Mazel, F. 2016. L'Évêque et le territoire. L'invention médiévale de l'espace. Paris: Éditions du Seuil.

Mériaux, Ch. 2008. "L'espace du diocèse dans la province de Reims du haut Moyen Âge», en F. Mazel (dir.), L'espace du diocèse. Genèse d'un territoire dans l'Occident médiéval: 119-142. Rennes: Presses Universitaires de Rennes.

Moore, M. E. 2011. A Sacred Kingdom: Bishops and the Rise of Frankish Kingship, 300-850. Washigton, D.C.: Catholic University of America Press.

Mor, C. G. 1979. "Sui poteri civili del vescovi dal IV al secolo VIII», en C. G. Mor y H. Schmidinger (eds.), I poteri temporali dei vescovi in Italia e in Germania nel Medioevo: 7-33. Bologna: II Mulino.

Morsel, J. 2006a. "Construire l'espace sans la notion d'espace. Le cas du Salzforst (Franconie) au XIV e siècle», en T. Lienhard (ed.), Construction de l'espace au Moyen Age: pratiques et représentations: 295-316. Paris: Publications de la Sorbonne.

Morsel, J. 2006b. «Appropriation communautaire du territoire, ou appropriation territoriale de la communauté». Hypothèses 9 (1): 89-104. https://doi.org/10.3917/hyp.051.0089

Moulet, B. 2017. "Limites et discontinuités à Byzance : le cas des territoires épiscopaux», en N. Baron, S. Boissellier, F. Clément y F. Sabaté (dirs.), Ériger et borner diocèses et principautés au Moyen Âge. Limites et frontières (vol. II): 45-59. Villeneuve d'Ascq: Presses Universitaires du Septentrion.

Orlandis, J. 1976. "Las relaciones intereclesiales en la Hispania visigoda», en La Iglesia en la España visigótica y medieval: 59-93. Pamplona: Ediciones Universidad de Navarra.

Painter, J. 2009. «Territory and Network: A False Dichotomy?», en M. Vanier (dir.), Territoires, territorialité, territorialisation: controverses et perspectives: 57-66. Rennes: Presses Universitaires de Rennes.

Pérez Martínez, M. 2000-2001. «La burocracia episcopal en la Hispania tardorromana y visigótica (siglos IV-VII)», Studia Historica. Historia Medieval 18-19: 17-40.

Pérez Sánchez, D. 2001. "Jerarquía eclesiástica y elementos socioeconómicos en el sur del reino visigodo de Toledo». Cassiodorus 6-7: 58-68. 
Pietri, Ch. 1997. «Chiesa e comunità locali nell’Occidente cristiano (IV-VI d. C.): I'esempio della Gallia», en A. Giardina (ed.), Società romana e impero tardoantico. Le merci, gli insediamenti, 3: 475521. Roma: École Française de Rome.

Poveda Arias, P. 2019. "Clovis and Remigius of Reims in the Making of the Merovingian Kingdoms». European Review of History 26 (2): 197-218. https://doi.org/10.1080/13507486.2017.139710.

Quirós Castillo, J. A. 2011. «Early Medieval Landscapes in North-West Spain: Local Powers and Communities, Fifth-Tenth Centuries». Early Medieval Europe 19 (3): 285-311. https://doi.org/10.1111/j.1468-0254.2011.00321.x

Raffestin, C. 1980. Pour une géographie du pouvoir. Paris: Lexis Nexis.

Rapp, C. 2005. Holy Bishops in Late Antiquity: the Nature of Christian Leadership in an Age of Transition. Berkeley: California University Press.

Rico Camps, D. 2009. «Arquitectura y epigrafía en la Antigüedad Tardía. Testimonios hispanos». Pyrenae 40 (1): 7-53.

Ripoll y Velázquez, I. 1999. "Origen y desarrollo de las Parrochiae en la Hispania de la Antigüedad tardía», en Ph. Pergola y P. M. Barbini (eds.), Alle origini della parrochia rurale (IV-VIII sec.): 101-165. Città del Vaticano: Pontificio Istituto di Archeologia.

Sablayrolles, R. 2002. "Les limites de la cité de Toulouse», en P. M. Pailler (dir.), Tolosa : Nouvelles recherches sur Toulouse et son territoire dans l'Antiquité: 307-326. Roma: École Française de Rome.

Sack, R. D. 1986. Human Territoriality: Its Theory and History. Cambridge: Cambridge University Press.

Salvador Ventura, F. J. 2012. «El centro de Andalucía entre los siglos V y VII: de las ciudades herederas de Roma a las sedes episcopales hispanogodas». Habis 43: 233-247.

Sánchez Pardo, J. C. 2010. «Las iglesias rurales y su papel en la articulación territorial de la Galicia medieval (ss. VI-VIII). Un caso de estudio». Mélanges de la Casa de Velázquez 40 (1): 149-170. https:// doi.org/10.4000/mcv.3374

Sánchez Pardo, J. C. 2013. «Iglesias y dinámicas sociopolíticas en el paisaje gallego de los siglos VI-VIII». Hispania 73 (243): 11-50. https:// doi.org/10.3989/hispania.2013.001

Sánchez Pardo, J. C. 2014. «Organización eclesiástica y social en la Galicia tardoantigua. Una perspectiva geográfico-arqueológica del Parroquial Suevo». Hispania Sacra 66 (134): 439-480. https://doi.org/10.3989/hs.2014.058

Sánchez Pardo, J. C. 2016. "The Creation of Ecclesiastical Landscapes in Early Medieval Galicia (Northwest Spain, Fifth to Tenth Centuries)», en T. Ó. Carragáin y S. Turner (eds.), Making Christian Landscapes in Atlantic Europe: 367-381. Cork: Cork University Press.

Sánchez Pardo, J. C. y Shapland, M. G. 2015. «Introduction: Churches and Social Power in Early Medieval Europe», en J. C. Sánchez Pardo y M. G. Shapland (eds.), Churches and Social Power in Early Medieval Europe: 1-33. Turnhout: Brepols.

Sánchez Ramos, I., Barroso Cabrera, R., Morín de Pablos, J. y Velázquez Soriano, I. 2015. "Topografía eclesiástica de la Bética en la Antigüedad tardía a través del corpus epigráfico». Romvla 14: 221-265.

Sassen, S. 2006. Territory, Authority, Rights: From Medieval to Global Assemblages. Princeton: Princeton University Press.

Schneider, L. 2008. "Aux marges méditerranéennes de la Gaule mérovingienne. Les cadres politiques et ecclésiastiques de l'ancienne Narbonnaise $\mathrm{I}^{\mathrm{re}}$ entre Antiquité et Moyen âge ( $\mathrm{V}^{\mathrm{e}}-\mathrm{V} \mathrm{I}^{\mathrm{e}}$ siècle)», en F. Mazel (dir.), L'espace du diocèse. Genèse d'un territoire dans l'Occident médiéval: 69-96. Rennes: Presses Universitaires de Rennes.

Sotomayor Muro, M. 1982. «Penetración de la Iglesia en los medios rurales de la España tardorromana y visigoda», en Cristianizzazione ed organizzazione ecclesiastica delle campagne nell'alto medioevo: espansione e resistenze, II: 639-670. Spoleto, CISAM.

Sotomayor Muro, M. 2002. "Sedes episcopales hispanorromanas, visigodas y mozárabes en Andalucía», en C. González Román y A. Padilla Arroba (coords.), Estudios sobre las ciudades de la Bética: 464-496. Granada: Universidad de Granada.

Sotomayor Muro, M. 2004a. «Términos de la organización territorial eclesiástica en los concilios hispano-romanos y visigodos», en C. Balmelle, P. Chevalier y G. Ripoll (eds.), Mélanges d'Antiquité tardive. Stvdiola in honorem Noël Duval: 283-297. Turnhout: Brepols.

Sotomayor Muro, M. 2004b. «Las relaciones iglesia urbana-iglesia rural en los concilios hispano-romanos y visigodos». Antigüedad y Cristianismo 21: 525-542.

Stocking, R. L. 2000. Bishops, Councils and Consensus in the Visigothic Kingdom, 589-633. Ann Arbor: The University of Michigan Press.

Torres López, M. 1925. "La doctrina de las 'iglesias propias' en los autores españoles». Anuario de Historia del Derecho Español 2: 402-461.

Ubric Rabaneda, P. 2004. La Iglesia en la Hispania del siglo V. Granada: Universidad de Granada.

Utrero Agudo, M. a A. y Moreno Martín, F. J. 2015. «Evergetism among the Bishops of Hispania between the Sixth and Seventh Centuries: A Dialogue between Archaeological and Documentary Sources». Journal of Early Christian Studies 23 (1): 97-131. https://doi.org/10.1353/earl.2015.0005

Vallejo Girvés, M. 2000-2001. «Las sedes eclesiásticas hispano-bizantinas en su incorporación al reino visigodo de Toledo». Cassiodorus 6-7: 13-35.

Vallejo Girvés, M. 2012. Hispania y Bizancio. Una relación desconocida. Madrid: Akal.

Van Dam, R. 1985. Leadership \& Community in Late Antique Gaul. Berkeley-Los Angeles-London: University of California Press.

Velázquez, I. 2007. "Baselicas multas miro opere construxit (VSPE 5.1.1). El valor de las fuentes literarias y epigráficas sobre la edilicia religiosa en la Hispania visigoda». Hortus Artium Medievalium 13 (2): 261-269. https://doi.org/10.1484/j.ham.2.305417

Wickham, Ch. 2005. Framing the Early Middle Ages. Europe and the Mediterranea, 400-800. Oxford-New York: Oxford University Press.

Wickham, Ch. 2009. «Bounding the City: Concepts of Urban-Rural Difference in the West in the Early Middle Ages», en Città $e$ Campagna nei secoli altomedievali: 61-80. Spoleto: CISAM.

Wood, I. 1999. "Social Relations in the Visigothic Kingdom from the Fifth to the Seventh Century: The Example of Mérida», en P. Heather (ed.), The Visigoths. From the Migration Period to the Seventh Century. An Ethnographic Perspective: 191-223. San Marino: The Boydell Press.

Wood, I. 2013. «Entrusting Western Europe to the Church, 400750». Transactions of the Royal Historical Society 23: 37-73. https://doi.org/10.1017/s0080440113000030

Wood, S. 2008. The Proprietary Church in the Medieval West. OxfordNew York: Oxford University Press.

Wood, S. 2014. «Bishops and the Proprietary Church, Diversity of Principal and Practice in Early Medieval Frankish Dominions and in Italy", en Chiese locali e chiese regionali nell'alto medioevo: 895912. Spoleto: CISAM.

Zadora-Rio, E. 2005. «Territoires paroissaux et construction de l'espace vernaculaire». Médievales 49: 105-120. https://doi.org/10.4000/medievales.1306

Zadora-Rio, E. 2016. «Parish Boundaries and the Illusion of Territorial Continuity in Landscape Archaeology: The Evidence from the Touraine», en T. Ó. Carragáin y S. Turner (eds.), Making Christian Landscapes in Atlantic Europe: 345-365. Cork: Cork University Press. 